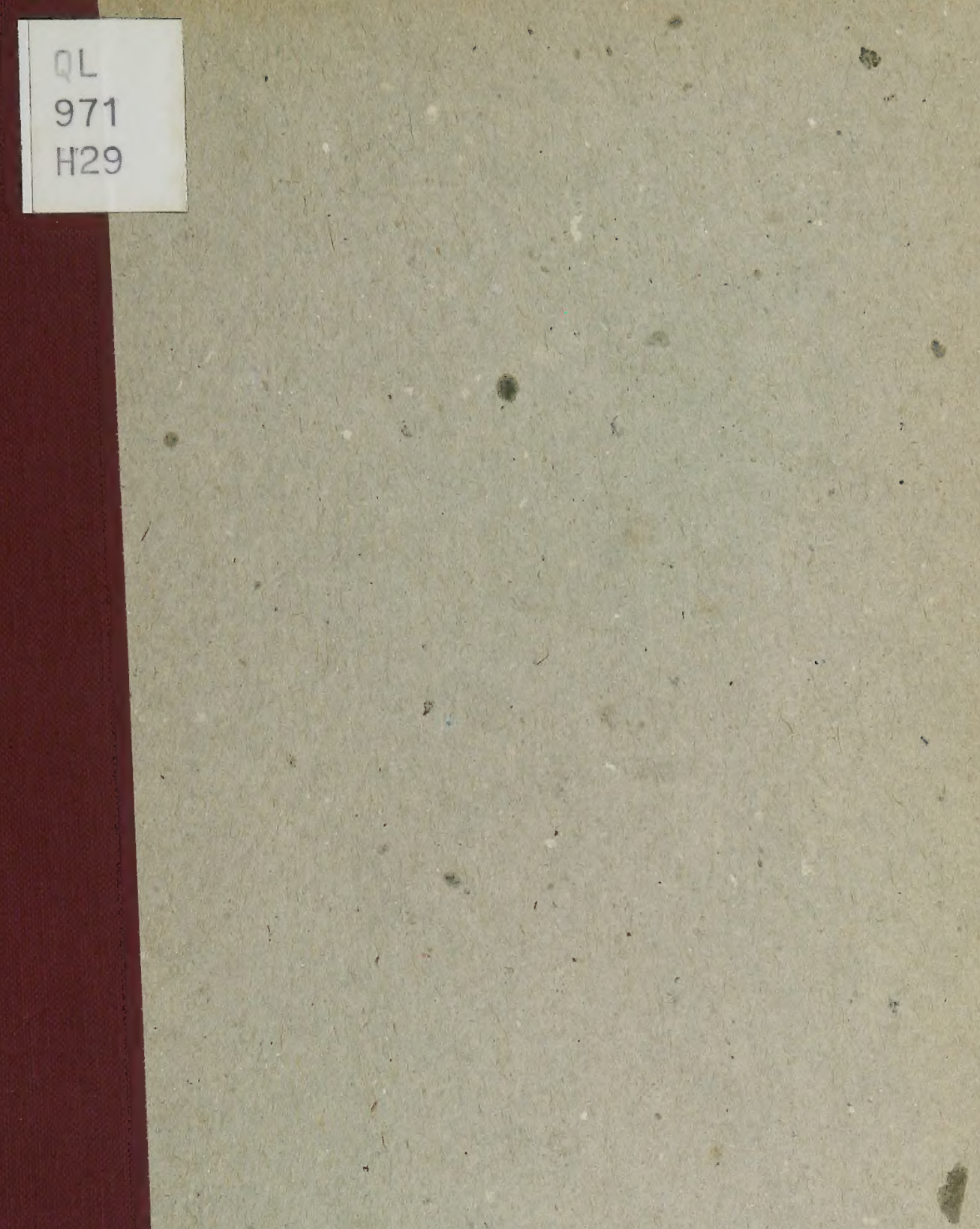




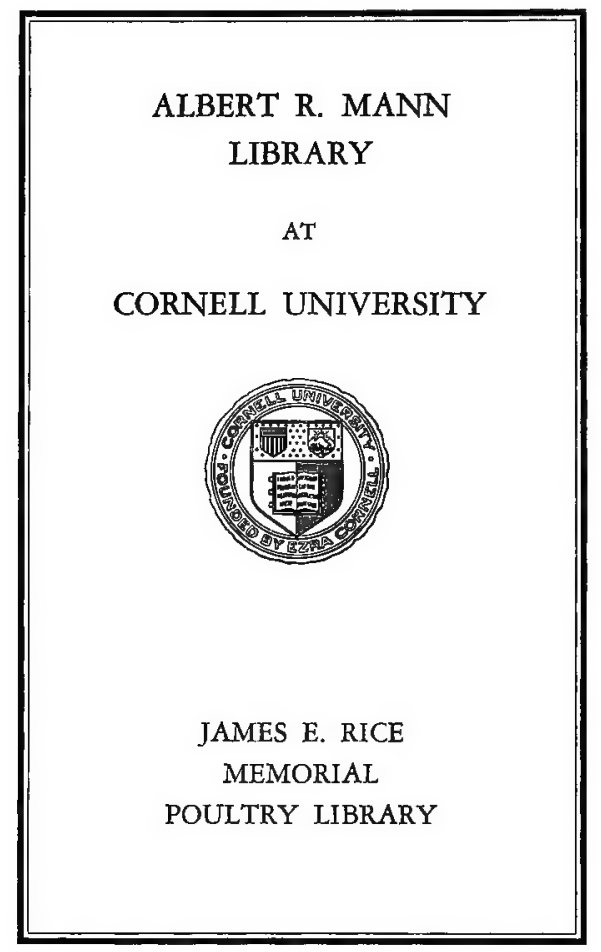


Cornell University Library

QL 971.H29

The fertilization and early development

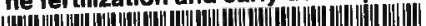

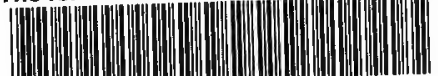

31924000401616 


\section{Cornell University Library}

The original of this book is in the Cornell University Library.

There are no known copyright restrictions in the United States on the use of the text.

http://www.archive.org/details/cu31924000401616 


\section{THE FERTILIZATION ANI EARLY DEVELOPMENT OF THE PIGEON'S EGG}

\section{A DISSERTATION}

SUBMITTED TO THE FACULTIES OF THE GRADUATF SCHOOLS OF ARM, LITERATURE, AND SOIENCE, IN CANDTACY FOK THE DEGREE. OF DOCTOR OF PHILOSOPHY

\section{ZOOLOGY}

BY

EUGENE HOWARD HARPER

CHICAGO

1902 



\title{
THE FERTILIZATION AND EARLY DEVELOPMENT OF THE PIGEON'S EGG
}

\author{
A DISSERTATION \\ SURMITTED TO THE FACULTIES OF THE GRADUATF SCHOOLS OF ARTS, \\ LITERATURE, AND SCIENCE, IN CANDIDACY FOR THE \\ DEGREE OF DOCTOH OF PHILOSOPHY
}

\section{ZOOLOGY}

BY

EUGENE HOWARD HARPER

\section{CHICAGO}




$$
E 15318
$$

QL
971
429 


\title{
THE FERTILIZATION AND EARLY DEVELOPMENT OF THE PIGEON'S EGG.
}

\author{
BY \\ EUGENE HOWARD HARPER, PH. D.
}

With 4 Double Plates and 6 Diagrams in the Text.

TABLE OF CONTENTS.

Introduction.

Methods.

Some observations on the breeding habits of the common pigeon.

The fertilization of the egg and its passage through the oviduct.

Some late stages of the ovarian egg.

Nucleoli in the ovarian egg.

The fertilized egg:

Maturation divisions.

Fertilization stages.

Early cleavage stages.

Development of the accessory nuclei (diagrams 1-6).

The yolk nuclei of later cleavage stages.

Polyspermy in other eggs.

Some features of mitosis in the pigeon's egg.

Conclusions.

Bibliography.

Description of plates.

Plates.

The investigation, the results of which are here described, was proposed to me by Dr. C. O. Whitman, and the work has been carried on under his direction, being designed as part of a more general work upon the Natural History of Pigeons. My thanks are due to Prof. Whitman for his encouragement and suggestions and his assistance in obtaining the material.

In this paper the aim has been to get a view of that period of development of the bird's egg which has hitherto been scarcely touched upon, including the maturation, fertilization and early cleavage. Material was obtained from only one species, the common pigeon, Columba livia domestica. On account of the prolonged breeding season of pigeons and the ease with which they may be kept in confinement, they are 
certainly better adapted to furnish material for studies of this sort than any other bird.

About the early development of the large meroblastic eggs comparatively little is known. This has remained true in spite of the thoroughness with which the embryonic stages of selachian and chick have been studied. As a result of the work of a number of investigators, chiefly Rückert, there is now a fairly complete general survey of the fertilization and early stages of the selachian egg. Observations upon the early development of the bird's egg are very few. Some of the early cleavage stages of the chick were figured by Coste, and Balfour contributed some observations. The internal phenomena of the egg during maturation, fertilization and early cleavage have remained an open field for investigation.

Upon the ovarian history of the bird's egg observations have been quite numerous. The paper of Holl, 9o, upon the hen's egg may be mentioned as one of the most important.

The development of the large meroblastic eggs obviously presents numerous problems. In this paper the stages of the egg obtained are scattered over a considerable period, and present glimpses of various phases of maturation, fertilization and early cleavage. A few stages of the ovarian egg have also been introduced.

\section{MeTHODS.}

The method followed has been to fix the whole egg before attempting to remove the germinal area. The oviduct is removed, the position of the egg being carefully noted, as this enables one to judge the approximate stage in development and determines the subsequent treatment in staining. The portion of the oviduct containing the egg is then cut off, immersed in the fixing fluid and slit open underneath the liquid. In case of an egg which is free in the body cavity, with some caution the body may be inverted over the fixing fluid, allowing the egg to drop out. The large ovarian egg may be fixed long enough to allow the fluid to penetrate the disc, then hardened in alcohol and the germinal area subsequently dissected out.

The choice of fixing fluids is somewhat limited, since many of them leave the disc too brittle to stand the subsequent treatment, and washing in water is undesirable. The picro-acetic mixtures have been chiefly used. Long fixation is not necessary or desirable, owing to the swelling of the yolk, which is apt to distort the disc.

It is well to cut out a considerable portion of the surrounding yolk with the disc and then to float this piece into a shallow watch-glass and 
allow it to remain with the convex surface down in the watch-glass through the washing and hardening treatment. Lying on a flat surface tends to warp and often crack the disc. It should be trimmed evenly all around to overcome the tendency to curl in one direction. Occasionally the egg membrane will come off easily before or even after fixation. If not, the sharpness of the knife must be depended on to overcome this difficulty. Of course the knife should strike the inner side of the disc in its descent.

The abundance of the yolk and its obscuration of other structures would seem to make it desirable to use a stain which should mask the yolk as much as possible. In all but the fertilization stages the nuclei are surrounded by areas tolerably free from granules, and this is especially true of the sperm nuclei in their later divisons, which are surrounded by very large granule-free areas. For this reason the iron-alum hæmatoxylin stain is workable, and possesses besides an advantage in differentiating certain areas in the cytoplasm during its amœboid changes, which are less conspicuous with a stain which masks the yolk. The different degrees of extraction of the stain in the different areas of the cytoplasm is a highly desirable feature.

\section{Some Observations on the Breeding Habits of the Common} Pigeon.

The fact that the pigeon breeds so readily in confinement makes possible a close observation of its breeding habits. As is well known, the special instincts displayed in connection with reproduction are more highly developed in the pigeon than in the common fowl. These complex instincts are associated with monogamy, which reaches a type of development in the pigeon which is very high among birds. For example, the feeding of the young with "pigeon milk" may be mentioned. It is only with the earlier manifestations of the reproductive instincts prior to egg-laying that we are here concerned.

It might be supposed that in the case of a domesticated bird breeding readily in confinement, such as the pigeon, some approach might be made toward an exact method for determining the time of fertilization of the egg. The time of egg-laying is approximately definite, as all breeders know. The common pigeon ordinarily lays two eggs at a sitting, occasionally only one. The first egg is regularly laid late in the afternoon. The second egg will be laid early in the afternoon of the second day following.

It is evident that the determination of the time of fertilization of the second egg of the pair and the length of time taken in its passage 
through the oviduct would be a simpler matter than to determine from external signs when the first egg is fertilized. It has been found that after the first egg is laid, in the course of a very few hours the second egg becomes detached from the ovary, is fertilized, and passes into the oviduct.

As stated above, the first egg is laid late in the afternoon. Early in the evening the second egg becomes free from its capsule in the ovary and enters the oviduct. In all cases observed this has taken place between seven and nine o'clock. The time taken in passing down the oviduct is relatively short, the far larger part of the time which elapses before the egg is laid being spent in the lower portion, known as the uterus, or shell-gland. It is evident that the second egg of a pair may be obtained at approximately any stage desired, beginning with a period a few hours before its fertilization.

The question arises whether there may be any criteria found for judging the time of fertilization of the first egg. It might be thought from analogy with the mammalia that the time of copulation would furnish such a criterion. It is quite plain from the regularity of the history of the second egg, as given above, that the exact period when the egg is freed from its capsule is dependent upon the female organization, and would be likely to occur at some definite period, probably at night. A moment's thought would, however, make it plain that it is highly improbable that a periodical receptivity, or period of heat, should be displayed by the female at this time. Experience of the writer has shown that any violent movement of the animal at this time is likely to result in a broken egg. Of course, such an egg as the bird's cannot be retained in the oviduct to await fertilization. Sperms are stored in advance, and the critical passage of the egg, after leaving its tough capsule in the ovary, through the oviduct till it acquires its coating of albumen and a shell, occurs at night when there are no movements of the animal to endanger its safety. The period of receptivity of the female is prior to this series of events. Copulation is repeated so often that no definiteness could be attached to it as a criterion. The question then arises whether the period of receptivity of the female has any definite duration, so as to indicate in this way when the maturation of the egg is taking place. From analogy with the mammal and with many birds, such as the common fowl, we commonly think of ovulation as exclusively a female function, going on regardless of whether the eggs produced are fertilized or not. Thus the common fowl produces unfertilized eggs regularly in the absence of a male. In the pigeon, however, ovulation is delayed until mating. When a mature pair ready 
for mating are put together, egg-laying ordinarily ensues at the end of a rather definite period, at the least eight days. The female functions are held in abeyance till the proper stimulus is received from a mate. The maturing of the egg is so exclusively a female function that it seems odd at first thought that an apparent exception should occur to the rule. Of course, we know that the final maturation of the egg, or the giving off of the polar bodies, awaits in most animals the act of fertilization. But here the effect is produced upon the egg by the entrance of sperms. How mating itself and the act of copulation could influence the ripening of the egg in the ovary is another problem. In this connection the curious fact must be mentioned that two female pigeons placed in confinement together may both take to laying eggs. The function of ovulation is in a state of tension, so to speak, that requires only a slight stimulus, "mental" apparently in this case, to set the mechanism to working. At any rate, it is impossible to regard the presence of sperm in the oviduct as an essential element of the stimulus to ovulation, although it may have an important influence in the normal case. Our attention is directed to the various and complex instincts of the male which come under the head of courtship, both before and after mating is effected, as furnishing a part of the stimulus to the female reproductive organs.

Phylogenetic considerations would lead us to consider the peculiar habits of the pigeon as recently acquired. The retention of ova in the unmated female, is in particular not very firmly fixed, as the facts stated show. The habits of the common fowl are certainly more primitive. In monogamous birds it might be expected that the function of ovulation would be adjusted so as to take place only after mating, inasmuch as it is probable that in a state of nature mating may be delayed for various causes, and the production of an unfertilized egg is no trifling loss, as in the mammal. In polygamous birds mating is sure to occur, and the female functions may be adjusted for continuous ovulation, with the practical certainty that in nature no unfertilized egg will be produced.

The complex reproductive instincts of the pigeon, displayed in their highest. form in the male, are matters of common observation among those who have observed pigeons, and need not be dwelt upon at great length.

As is well known, the strutting of male pigeons is not simply a feature of courtship and rivalry among males. It is continued until egglaying begins, and is accompanied by a less active similar manifestation by the female. It is in fact an accompaniment of the whole period 
from mating to egg-laying, during which copulation is of frequent occurrence.

There is an act which regularly precedes copulation, in which there is an apparent regurgitation of some secretion by the male which is taken from his throat by the bill of the female, in somewhat the same manner as the young birds take their food. It is a less violent manifestation than the feeding of the young, however. It is easy to see that here may be one of the sources of indirect stimulation to the female reproductive organs.

The male has the habit of frequently taking to the nest and calling the female by emitting a low growling noise and gently vibrating his wings. It is evident from a consideration of the complexity of these and other instincts, such as nest-building, that the initiation of reproductive activity in the female can ordinarily only be dated from the time of mating, or from the resumption of activity by an already mated pair. The female pigeon is either a very dull bird or a very exacting one, requiring constant attention and flattery to rouse her to her proper functional activity, or else the male must be accused of greatly magnifying his office.

There is a possibility that the nesting habits of the female could be used as a clue to the time of egg-laying. The female has the habit of sitting on the nest occasionally for some time before the first egg is laid, but in practice this has not been found to give sufficiently definite data.

No certain method has been found for determining the time of fertilization of the first egg. By making use of the second egg, any stage after or shortly before fertilization may be obtained. This method has the disadvantage of yielding only one early stage of the egg from each bird. The first egg when laid has reached the close of the segmentation period. The second egg would remain in the oviduct nearly forty-eight hours after the first was laid. To obtain a series of the late ovarian eggs is more a matter of chance.

In elasmobranchs and reptiles a considerable number of eggs are found in the oviduct and all in nearly the same stage of development. The greater certainty with which the pigeon's egg may be obtained is a compensatory feature, when we are considering the relative difficulty of obtaining material for a study of these forms.

The Fertilization of the Egg and Its Passage through the OVIDUCT.

The passage of the egg through the oviduct until it acquires a thin shell within the lower portion, or shell-gland, is a nocturnal function. 
That, as such, it is adapted to secure the safety of the egg is evident from the thinness of the egg membrane when it leaves its tough ovarian capsule and its consequent liability to be ruptured at this critical period. Careful handling is necessary to secure the egg at this time. The capsule of the egg splits along the pole opposite to its attachment in the ovary. A gradual thinning out of the capsular wall occurs along the line of splitting, causing a pale streak across the egg. The vessels of the capsular wall are at this time highly charged with blood. Two such pale streaks across the egg have been seen at right angles. During the rupturing of the capsule, the egg bulges out in various places, producing an irregular appearance with several protuberances. Inasmuch as the wall grows quite thin during the process, it is quite possible that the spermatozoa may be able to penetrate and reach the germinal vesicle before the egg leaves its capsule: When the egg escapes, it is found well surrounded by a thin albuminous liquid with which the body cavity at this time is charged. It is like the albuminous secretion of the oviduct, except that it is much thinner. This liquid serves both as a medium for the spermatozoa, as stated by Balfour, and as a support to the egg at this critical juncture, when it is invested by only a very thin membrane.

The egg membrane or yolk membrane is about $3.5 \mu$ in thickness. The outer margin of the cytoplasm is somewhat denser and also talres on something of the character of a membrane. In some preparations this is found actually separated for a little way from the underlying cytoplasm. But for the most part it appears. like a very thin non-separable layer.

The egg membrane appears structureless. It seems to increase in tenacity, since, when the egg is first set free from its capsule, it is very easily ruptured. The flattening of the yolk from its own weight in the fixing fluid is enough to cause the rupturing of the membrane. The increase in tenacity later may be the effect of the deposition of closely adhering layers of albumen.

The egg is clasped by the funnel-like mouth of the oviduct, which at this time has been observed to display active peristaltic contractions, as if in the act of swallowing the egg. The contractions were confined to the funnel portion of the oviduct. The fact as stated rests upon a single observation. As the transition from the funnel to the glandular portion is abrupt, it would seem that the egg must be engulfed by muscular contraction, but after it is within the glandular portion of the oviduct it is driven simply by ciliary action along its spiral course through the oviduct, as has been stated by Cushny, o2, in regard to the hen's egg. The peristaltic motions were sufficiently active to be unmistakable. The 
desire to obtain the egg interfered with the continued observation of the movements, and it is not known how long they might continue. Morgan, 97, states that the old view that the frog's egg is swallowed by peristaltic motions of the infundibulum of the oviduct is probably mistaken, and that the egg is doubtless driven along its entire course by ciliary action. The oviduct of the pigeon is usually from twelve to fifteen inches in length, but sometimes over twenty inches. The funnel portion or infundibulum is less than one-fourth of the entire length; the glandular portion which secretes the albumen is a little less than one-half of the ordinary length. The remaining portion, the uterus or shell-gland, is separated from the preceding part by a definite constriction.

The entrance of spermatozoa is previous to the time when the egg is clasped by the funnel of the oviduct. An egg at this stage contains numerous sperm nuclei which have undergone considerable transformation and others in various early stages of transformation. Hence the entrance of spermatozoa must take place as soon as the germinal disc is exposed by the rupture of the follicular wall. This may be while the egg is still attached to the ovary, but the point has not been definitely ascertained.

The stage of development reached by the egg at any time is indicated approximately by its position in the oviduct. Thus the polar bodies are given off within the proximal part of the glandular portion, and cleavage begins just about as the egg enters the shell-gland. The passages through the upper portion of the oviduct in which the albumen is secreted is relatively rapid. The following table gives some data for an estimate of the time.

Beginning of first maturation division........ \%:40-9:00 P. M.

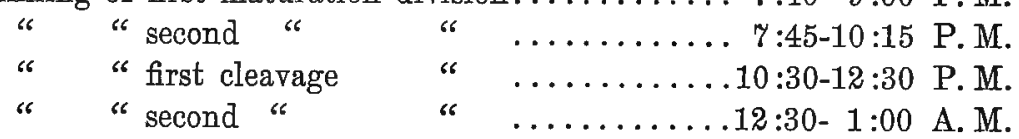

From such data only a rough estimate can be made as to the time elapsing between the impregnation of the egg and the first cleavage. Balfour, 85, states that in the fowl cleavage of the egg begins just before it enters the shell-gland. There is consequently a close similarity between the pigeon and the fowl in this respect. Since the absolute length of the oviduct varies in different birds, it would hardly be expected that the same relative position in the oviduct would generally be reached by the egg at the same stage of development. As a matter of fact the observed cases so far have been so close to the average as to furnish no evidence as to variation in this respect. 


\section{Some Late Stages of the Ovarian Egg.}

The growth of the ovarian egg may be roughly divided from one point of view into two periods. The first is a long one of very slow growth, the second is a short period in which the main increase in size of the egg is effected. Two eggs mature at a time, occasionally only one. The second pair in order of development are usually quite small; the larger being ordinarily several millimeters in diameter when the first pair are mature, but it may be half-grown occasionally at this time.

The full-sized egg in its capsule is nearly an inch in diameter. In Fig. 1 is shown the nucleus of an egg $1.4 \mathrm{~mm}$. in diameter. It measures $238 \mu$ in diameter, and, being nearly spherical, is greater in volume than the nucleus of an egg which was in the midst of its rapid growth and $15 \mathrm{~mm}$. in diameter. The latter nucleus is lens-shaped, flattened against .the follicular envelope, and its diameter is $378 \mu$ (Fig. 3 ). In a smaller egg $12 \mathrm{~mm}$. in diameter the nucleus is shown in horizontal section (Fig. 2b). Its greater diameter is $329 \mu$. The ground substance of the nucleus or germinal vesicle is of a finely alveolar character, appearing under a low power to contain only a few scattering deutoplasmic granules. Under a higher power, however, it is seen to be thickly studded with microsomes of the same character as the larger granules. The chromosomes are in a group in a somewhat eccentric position, surrounded by a system of radiations. Apparently pairs of dumbbell-shaped dyads are lying side by side. They are unequal in size, three of the pairs being considerably larger. Two of the pairs are crossed, lying very close together (Fig. 17). There are numerous glistening refractive bodies scattered among the chromosomes, some small and some in vesicular masses. At the center of the germinal vesicle is a considerable amount of chromatic staining material in the form of short threads, and also a group of rounded bodies like nucleoli lying underneath them. The nucleoli in some cases have short remnants of chromatic threads clinging to them.

A later stage is shown in Figs. $4 \mathrm{a}$ and b. In Fig. 4a the whole germinal area of this egg is shown, the germinal vesicle enlarged in Fig. $4 \mathrm{~b}$. This egg was the older of a pair, the nucleus of the younger of which is shown in Fig. 3. A comparison of the size of the nuclei shows a great diminution. The wall of the nucleus is seen to be breaking down. Its contour is no longer regular, but it has shriveled up and retreated from its manifestly former position. The disintegrating wall is surrounded by a zone of the nuclear ground substance. The diameter to the outer limits of this zone is $210 \mu$, showing an invasion of the yolk 
into the area formerly occupied by the germinal vesicle. The retreat of the nuclear wall is unlike ordinary plasmolysis from fixing agents. There is no vacant space left from the shrinking of contents. Such plasmolysis is evident in the case of the younger egg of the pair, Fig. 3, indicating a more watery condition of the nucleus in the younger and still rapidly growing egg. In this egg there are no remnants of threads, except for slight indications upon the more or less rounded nucleoli. The refractive bodies previously mentioned are present. The chromosomes are shortened as compared with the former instance and are irregularly placed. The deutoplasmic microsomes in the nuclear ground substance are less prominent owing to a greater extraction of the stain.

Underneath the germinal vesicle is a core of lighter staining material, extending inward to the bed of white yolk. The whole germinal area under a low power appears very finely granular compared with the coarse underlying yolk.

The next stage obtained is that of an egg which in the ordinary course of events would have become free from its capsule and passed into the oviduct in the course of several hours. To be more definite in this instance, the egg was taken from the ovary at $7: 00$ P. M., the first egg having been laid in the afternoon.

The cross section (Fig. 5) shows the equatorial band of chromosomes lying obliquely to the surface of the egg at the margin of the deutoplasmic area. There is an accumulation of a liquid substance at this point between the follicular wall and the granules, which, as in other eggs, may be called the perivitelline liquid.

The area occupied by the germinal vesicle is obliterated. There is very little if any difference in the appearance of the germinal area at this point, except for the perivitelline liquid above mentioned, and a much greater accumulation of a substance having seemingly the same character directly underneath the finely granular layer. This body of more liquid protoplasm appears in structure and staining properties like the contents of the former germinal vesicle. It fills a wider area, however, and is bounded beneath by the coarsely granular yolk. Two eggs were obtained at this stage, both showing the same appearance. It does not appear like an artefact, and though peculiar to this stage of the egg, it seerns to be definitely related with later changes in the fertilized egg.

No stages were obtained between those shown in Figs. $4 \mathrm{~b}$ and 5 . Fig. 5 shows the acme of development of the ovarian egg. If the accumulation of granule-free protoplasm underneath the granular layer of the disc is derived from the contents of the germinal vesicle, as its appearance would indicate, it seems as if a centripetal movement of this sub- 
stance had taken place simultaneously with a lateral invasion of the granular protoplasm. Possibly the path of this centripetal movement is indicated directly beneath the contracting germinal vesicle in Fig. $4 \mathrm{~b}$. Fig. 5 represents the stage supposedly when activity in the egg has reached a minimum. When activity is resumed in the maturation stages attention will be called to the fact that the underlying bed of granulefree protoplasm has disappeared and in its place is a cone-shaped active area (Fig. 8) extending clear to the periphery of the egg with the spindle at its apex. This would seem to indicate a centrifugal movement of the granule-free area at the time of giving off of the polar bodies.

The spindle is fully formed in this egg, although its oblique position makes it difficult to recognize the achromatic structures. The equatorial band of chromosomes shown in Fig. 18 is from the other of the two eggs above mentioned, and the section was almost parallel with the equatorial plate. The chromosomes appear as tetrads of unequal size. There is an appearance peculiar to the first polar spindle to which attention is called. There are within the circle of chromosomes and lying in the same plane, a number of deeply staining granules at the nodes of the linin network. They plainly differ from the deutoplasmic granules ontside, having the staining properties of chromosomes or centrosomes. There are four or five especially large ones at the center.

Nucleoli in the Ovarian Egg.-The nucleoli which have been described in this later part of the ovarian history are, as has been stated, evidently derived from a chromatic network which becomes aggregated into rounded masses, and these soon undergo dissolution in the form of refractive bodies. Lebrun, 02, describes nucleoles derived from the granular chromatin which are present at the first appearance of maturation in the egg of Diemyctilus and speaks of their propensity to fuse together.

In the amphibian egg, King, or, mentions the occurrence of such refractive bodies in the germinal vesicles. They are described as "yellowish green refractive bodies," which result from the disintegration of nucleoli. It seems likely that the small refractive bodies among the chromosomes are remains of nucleoli which are nearly disintegrated. The larger aggregations of refractive bodies and nucleoli found elsewhere in the germinal vesicle are in an earlier stage of the disintegrating process ( $b$ and $c$ in Fig. $4 b$ ).

The nucleoli which change to refractive bodies and disappear have a different fate from the nucleoli in the previous history of the germinal vesicle. According to Carnoy and Le Brun, in the amphibian egg the nucleoli are aggregations of the chromatin network, which at definite periods break down and give rise once more to a chromatic thread. They 
are a resting stage of the chromatin. According to the opinion of Wilson, oo, such nucleoli are to be regarded as chromatin masses distinct in nature from true nucleoli or plasmosomes. In the smaller pigeon ova such net-knots of chromatin are frequently seen, looking like the beginning of the formation of a nucleolus or the contrary, the unrolling of one to form a thread (Figs. 1a and b). But better evidence on the nature of these chromatin nucleoli may be obtained from other material than the pigeon. Without going too far afield from the purpose of this paper, it may be mentioned that the ova of the sparrow in the winter condition give an excellent example of chromatin aggregated into the form of nucleoli. There is an almost entire disappearance of the chromatin network and a large and variable number of nucleoli having the staining reaction of chromatin. This phenomenon is accompanied by a watery condition of the nucleus as shown by the great plasmolyzation from fixing agents. The eggs may be fixed so as to show no distortion, but the nuclei are invariably plasmolyzed.

This condition disappears when the growing season recommences in March. The chromatin threads reappear and the nucleus is no longer so easily plasmolyzed. The difference between the pigeon and the sparrow ova is accounted for by the fact that the ovary of the sparrow is in a resting state in the winter, while the breeding season of the pigeon, in comfortable quarters, is continuous except for a slight cessation in the fall, during moulting. If the view of Carnoy and Le Brun is correct, the evidence for the continuity of the chromosomes through the ovarian development alleged by Born, 94, must be mistaken.

A frequent appearance found in the pigeon ova was that of pale, broken-down nucleoli, looking rather like the " shells" of nucleoli, either insicle the nucleus or outside close to the membrane. This appearance is entirely different from that of the previously described refractive bodies. Such bodies are described by Carnoy and Le Brun in the amphibian egg.

\section{The Fertilized EgG.}

Maturation Divisions. - The earliest stage of the fertilized egg obtained is shown in horizontal section in Figș. 6a and b. The surface appearance of the disc of such an egg is shown in Fig. 6. The slightly oral disc has a greater diameter of $3.5 \mathrm{~mm}$. It is divided into two zones quite clearly distinguished in opacity, the outer zone being due to the abrupt thinning out of the fine granular matter of the dise. With a liand-lens the region of the nucleus may be made out in the living egg as a spot surrounded by a lighter ring or halo, the "fovea." The whole affected area surrounding the nucleus is shown in Fig. 6a. The nucleus 
is in the center of a granular area which is surrounded by a hyaloplasmic zone. The inner ring of the zone of hyaloplasm is quite free from granules and here the sperm nuclei are imbedded. Outside of the clear ring the cytoplasm is less densely granular and there is an appearance of watery rays or channels passing out. The diameter of the affected area is about .5 mm. One side is more vacuolated and hyaloplasmic than the other, which fact will be recalled in connection with later appearances during development. There is a rather clearly marked ring which is not like the hyaloplasmic ring in appearance, but is filled with a ground substance having a more finely alveolar structure. This ring, which may be called the "polar ring," will be better described in connection with vertical sections of the disc. The sperm nuclei shown in this section are in an advanced stage of transformation, and their identity with entering sperms must be discussed further later on.

The egg nucleus is in the equatorial plate stage (Fig. 19). There are eight apparent tetrads (pairs of dyads) in a ring, the diameter of which is greater than in the mature ovarian egg. The chromosomes also are larger, and are of unequal sizes as before. The central spindle granules are present, lying in the plane of the chromosomes, at the nodes of the linin network. The central group of larger ones is conspicuous, as in the previous instance. It may be again stated that these granules have not been found in any other spindles than the first polar, and, as already mentioned, they present a similar appearance in the four observed cases. They would seem to be concerned in some way with the formation of the first polar spindle, and may indeed be condensations of the linin network at the foci of the system of radiations surrounding the group of chromosomes before the formation of the spindle (see Fig. 17), though this may sound like a rash suggestion, since the stages in the formation of the spindle are yet to be observed. If they are "accessory" chromatin material, they evidently do not undergo dissolution like the chromatin nucleoli.

The nuclei embedded in the hyaline zone are all of similar structure and staining properties. They vary in size from four to seven $\mu$. They are of irregular shapes and do not have any bounding membrane. No asters have been found, but want of material has prevented the use of various staining methods. Those which have penetrated deeper are somewhat larger. Stages in the transformation of the sperms are shown in Figs. $\mathrm{ra}-\mathrm{h}$. The entrance of sperms seems to take place anywhere within the affected area, but those which enter the hyaline zone seem to undergo a more rapid development. The fate of the great majority of sperms can best be inferred in lack of direct evidence from the numbers found 
in the fertilization stages, where in the cases obtained the number was from 12 to 25 . Apparently those not entering at the right time and place meet with some unfavorable influence hindering their development.

In the perivitelline liquid are found numerous large cells from the follicular membrane of the ovarian egg (Fig. $7 i$ ). These cells are without walls, but the nucleus and accompanying body of cytoplasm bears an unmistakable resemblance to the follicular cells. Associated with them are found also blood corpuscles. From their size and appearance they may be distinguished from the sperm nuclei, since they are of a much greater order of magnitude. There is much nuclear debris which is evidently derived from these cells also present in the perivitelline space, showing that their fate is to degenerate. Rückert, 99, has found the same " inwandering follicular cells" in the selachian egg.

A vertical section of the germinal disc during the maturation stage is shown in Fig. 8. The egg was taken from near the beginning of the oviduct. The section contains the second polar spindle, and first polar body, situated at a slight depression in the surface of the disc. The vertical section of the germinal disc shows that the central or affected area has the shape of a cone with the spindle at the apex. The distinguishing characteristic of the affected area which mark it off from the surrounding homogeneous appearing disc, is its lighter staining property. This seems due both to the relative fewness of the granules and the greater extraction of the stain from those present. The protoplasmic ground-work is apparently more watery, and vacuoles are very numerous. The finely granular material of the disc surrounding the affected area retains the stain with great tenacity. The deeply-staining layer is quite sharply marked off from the underlying yolk, which loses its stain completely. The deeper yolk composed of very large granules, retains the stain, and thus there is a lighter area sandwiched between two dark staining regions. This may be seen in the section of the ovarian egg (Fig. 4a). The " polar ring" mentioned previously is seen to be shallow, appearing in crosssection as two lighter staining $V$-shaped areas outside of the apex of the affected area. The distinctness and conspicuous character of this ring make it evidently something more than an accidental feature. It can be traced through adjoining sections and shown to be a complete ring. Similar appearances in other eggs will be recalled, as, e. g., in that of the leech.

Turning to the nuclear phenomena at this stage, we see that the spindle lies close to the egg membrane. Centrosomes are inconspicuous, but a radiating arrangement of the alveoli may be made out at the poles. The spindle is in the equatorial plate stage (Fig. 22). 
In another egg we find the chromosomes just separating (Fig. 23). There are eight pairs, and they are quite unequal in size, as was shown in the first polar spindle. They show a marked increase in size compared with those of the first division. The spindle here lies in a decidedly lighter staining area. The polar globule fills a bowl-like depression in the disc instead of a position at the side of the depression, as in the previous case shown. The eight dyads in the polar body are not fused together, and some retain a slightly dumb-bell like shape. The wall of the polar body is well marked. The polar ring was present in this, as in all of the other maturation stages obtained after impregnation of the egg.

The second maturation spindle is shown in Fig. 21 in a slightly earlier stage. The spindle is not yet completely reformed. One of the chromosomes lies between the equatorial plate and the egg membrane not yet being drawn into position. It has the appearance of a tetrad, in which case it would be a chromosome of the first division which failed to divide. It is, however, probably a dyad in the first stages of splitting. The chromosomes as shown above are originally pairs of dyads lying closely side by side. The polar globule is in this case more rounded than in the last, which is undoubtedly due to its not yet having had time to become flattened by the pressure of the egg membrane

One other stage of the second maturation spindle is shown in Figs. 9 and 24 . In this egg the central core of the affected area directly underneath the spindle is different from the other cases obtained, being entirely free from deutoplasmic granules.

The egg nucleus is shown in Fig. 25 with the second polar globule just given off. The chromosomes are fused together into a mass with a somewhat crenate contour. The polar globule is still connected with the egg by a cytoplasmic neck, and its wall is not formed. The egg nucleus has penetrated the egg farther than is found to be the case in some later stages, but this may be explained by the exceptional fewness of yolk granules in the affected area which ordinarily might hinder its freedom of movement.

The further reconstructed egg nucleus is shown in Fig. 26. Both polar bodies are shown, being present in adjacent sections. The inner sphere and centrosome (?) is in this case recognizable and appears larger than during division. The egg nucleus does not have a distinct membrane.

Fertilization stages.-In a still later stage the egg nucleus is seen to be completely reconstructed and has a distinct membrane (Fig. 27). Yolk granules crowd about it so as to hide any other structures. The polar bodies were both found in the same section. The one which is farther 
from the egg nucleus has the chromosomes nearly all fused together. The nearer one is a fused mass of chromatin with a ragged outline showing a decided tendency to form a network. In displaying this tendency it resembles its sister nucleus in the egg. It tends to enter a metabolic phase. The first polar body, on the other hand, retains the kinetic tendency like the second maturition spindle, although it fails to divide.

The polar ring is present at this stage, but has not been found later than this, being apparently obliterated by cytoplasmic movements occurring within the affected area.

The sperm nuclei which are found in this egg are rather faintly staining bodies and no one of them is especially near to the egg nucleus.

The next stage obtained shows the pronuclei very near together, one being slightly smaller and deeper in the egg (the male?) There is a hyaline area adjoining, but no distinct astral appearance (Fig. 10).

In a later stage the pronuclei, about the same size as in the last instance, are seen in contact (Fig. 11). A diagram (Diagram 1), shows the other sperm nuclei present and their distribution. Only one, and it a quite large one, is in the affected area, the rest being scattered away from the center in all directions.

At a later stage the conjugating nuclei are flattened against each other (Fig. 12). The cytoplasmic surroundings of the disc are shown in the drawing. The peculiar orientation of the lighter staining central area in the form of a cone which was seen in the maturation stages is not any longer manifested in any of the fertilization stages. There is a considerably vacuolated area at one side of the pronuclei and on the other side a curious apparently normal appearance like a hyaline channel extending from the vicinity of the nuclei toward the egg surface. Astral appearances if present are hidden by the yolk. The number of sperm nuclei shown in the diagram (Diagram 2), is only twelve, which is probably too small, as the series of sections was imperfect.

When the segmentation nucleus is formed the accompanying cytoplasmic changes in the germinal disc are so striking as to indicate plainly the approach of division (Fig. 13). The affected area is spread out laterally and shows a differentiation into a more hyaloplasmic margin and a granular interior. This fact is, however, still more clearly perceived by reference to a surface section as shown in the subsequent stage (Fig. 14). The segmentation nucleus (Fig, 13) lies near the center of the affected area, rather closely surrounded by yolk granules. It has moved nearer to the egg surface than at the time of copulation. There are no sperm nuclei remaining within the affected area, but a pair are to be seen a little distance outside of its margin. The segmentation nucleus may be 
identified by its size and the appearance of the chromatin, as well as by its surroundings. It has a well-developed double contoured membrane. The contents are slightly plasmolyzed, a feature which has not been observed to occur at any earlier stage. The chromatin is beginning to be gathered into long threads.

The First Division.-A later stage containing the prophase of the first cleavage spindle is shown in Fig. 14, in horizontal section. The spindle lies at the center of a small area free from granules (Fig. 28). Centrosomes and asters are very indistinct, as would be expected at this stage of division. The centrosome is not a deeply staining granule. The cytoplasm shows only indistinct radiations. The spindle is rounded at the ends and rather broad. The chromosomes, sixteen in number, are partly in the equatorial plate. None of them are yet splitting. The prevailing shape of the chromosomes is that of a broad V. In the surrounding protoplasm may be seen the same appearances as in the stage of the segmentation nucleus (Fig. 14). There is an area of protoplasm whose outer border is hyaline and the center surrounding the nucleus is more granular. The area is elongated in the direction of nuclear division. Its margin shows an appearance like that of outpushings. These are large lobes, as if indicating an amceboid movement of the whole mass. Curiously enough, the granular interior conforms to the same outline, showing lobes corresponding to the outer margin. Balfour, 85, states that "In elasmobranchs before segmentation commences, the germinal disc exhibits amœboid movements." Here these amœboid movements, if so the appearances described are to be interpreted, are seen to be confined to a region at the center of the germinal area whose diameter is about $0.5 \mathrm{~mm}$., or about one-sixth the diameter of the inner area of the disc. The area of active protoplasm is differentiated into a more granular and a more hyaline pole. There are indications of a constriction which, if carried out, would thus divide the cytoplasm of the area qualitatively.

A stage of the first division is shown in Fig. 15, in which the nuclei are separated a considerable distance. They are of quite small size. The affected area of protoplasm shows a dumb-bell shaped figure and the nuclei lie at about the centers of the two ends. The hyaline outer border and the inner granular condition is still preserved. The first furrow is being formed at the constriction, but is shallow and does not appear in the section containing the nuclei. In the surface section it is seen as a broad, shallow depression filled with cytoplasm of a finely alveolar structure. Around the affected area lighter streaks may be seen extending out into the surrounding protoplasm. One blastomere is seen to be more hyaloplasmic than the other. 
The nuclei and first furrow have been found at a stage when the nuclei are very much larger. They had moved apart relatively little compared with the former stage, while they had greatly increased in size. If the small size at the former stage indicated that little time had elapsed since division, then their movements at first must have been more rapid. Perhaps the cytoplasmic constriction would be the cause of the early, rapid separation of the nuclei. Whatever may be the link connecting nuclear with cell division, it would seem that the constriction of the cytoplasm must play a part in the separation of the nuclei. At this stage, the completion of the first division, there is no differentiated area about the nuclei recognizable. Apparently the amoboid changes cease during the resting stage of the nuclei.

The Second Division.-In Fig. 16 is shown the beginning of the second division. The first furrow is longer. The nuclei are about equidistant from it. The spindles are formed and are in the prophase, approaching the equatorial plate stage. They lie in small areas free from granules. The differentiation in the cytoplasm is like that surrounding the first cleavage spindle, except for greater complexity. There is a clearly marked polarity. One blastomere is more granular, the other more hyaloplasmic. In the latter there is a complex affected area surrounded by homogeneous protoplasm. The hyaline border of the active area is even more distinct than at the first division. But this blastomere must apparently be identified with the more hyaloplasmic pole at the first division. The hyaline border shows a sinuous contour. The whole area is elongated, as before, in the plane of the next nuclear division. The prominences or outpushings are more complex. They correspond somewhat at the two poles, but are more developed at one pole (the left). There is an evident beginning of constriction, and division at this point would separate again a more hyaloplasmic blastomere from a more granular one. In the other blastomere the affected area has an even contour. One other egg was obtained at this stage and shows the same general features, but with minor differences in the apparent amoboid changes. It would hardly be expected that amoboid movements of this character would give rise to identical appearances in different eggs. The observation of Whitman, 87, on cytokinetic phenomena in general may be quoted in this connection: "They are diversiform in the extreme, rarely presenting regular form series, and thus stand in marked contrast with nuclear metamorphoses, which everywhere, both in plant and animal cells, exhibit a most remarkable uniformity."

Comparison of Cleavage and Maturation Divisions.-The appearances here described in connection with cleavage may be compared with the 
maturation divisions. The body of active protoplasm is differently oriented in the two cases, as has been pointed out. During maturation the active protoplasm underlies the spindle and extends radially in the egg, widening centripetally, so that its appearance is roughly that of a cone from the apex of which the polar bodies are pinched off. At cleavage, the area assumes a horizontal position with reference to the surface, and a constriction occurs at its middle. At the first maturation division (Fig. 6a), the spindle lies at the center of a granular area encircled by a hyaline zone. From analogy with the cleavage divisions, it would appear that this hyaline zone is a normal cytoplasmic feature of the maturation division. Within it lie many sperm nuclei and it is the favorable zone of entrance for the male elements. It would thus appear to have a double function, the relations of which are not, however, necessarily close, since the entrance of spermatozoa is not confined to this zone. In the second maturation division the hyaline zone around the spindle seems less conspicuous than at the first.

Kupffer, 75 and 9o, pointed out that the primary differentiation of protoplasm seen in the unicellular organism, into an outer hyaline and an inner granular protoplasm surrounding the nucleus, is also found in the animal tissue cell and egg. In the egg of petromyzon, as shown by Böhm, to which Kupffer, 9o, made especial reference, this differentiation is clearly shown. The hyaloplasm, which during fecundation appears as a cap upon the egg, later moves back into the yolk and undergoes further amceboid changes, elongating in the direction of nuclear division. The behavior of the sphere substance in the egg of unio, as described by Lillie, or, may be compared with that of the active protoplasm in the pigeon. The sphere substance results from the growth of the egg centrosome and sphere, and extends across nearly the whole diameter of the egg, elongating in the plane of nuclear division. In the pigeon's egg one stage was found, of the partially reconstructed egg nucleus, where the centrosome and sphere appeared greatly enlarged, as described by Lillie (Fig. 26). Conklin's demonstration of protoplasmic currents in the egg of crepidula may be mentioned in this connection. As mentioned above Balfour states that in the selachian egg amœboid movements occur before cleavage begins. Whitman, 87 , insisted that the cytoplasm could not be regarded merely as a passive nutritive substance, although, as he said, the majority of writers are inclined to seek the primum mobile in the nucleus and to make the nucleus responsible for the kinetic phenomena displayed in the cytoplasm."

Loeb, 95, relying upon Quincke's experiments and certain experiments of his own upon the echinoderm egg, ascribes cell-division to diffusion 

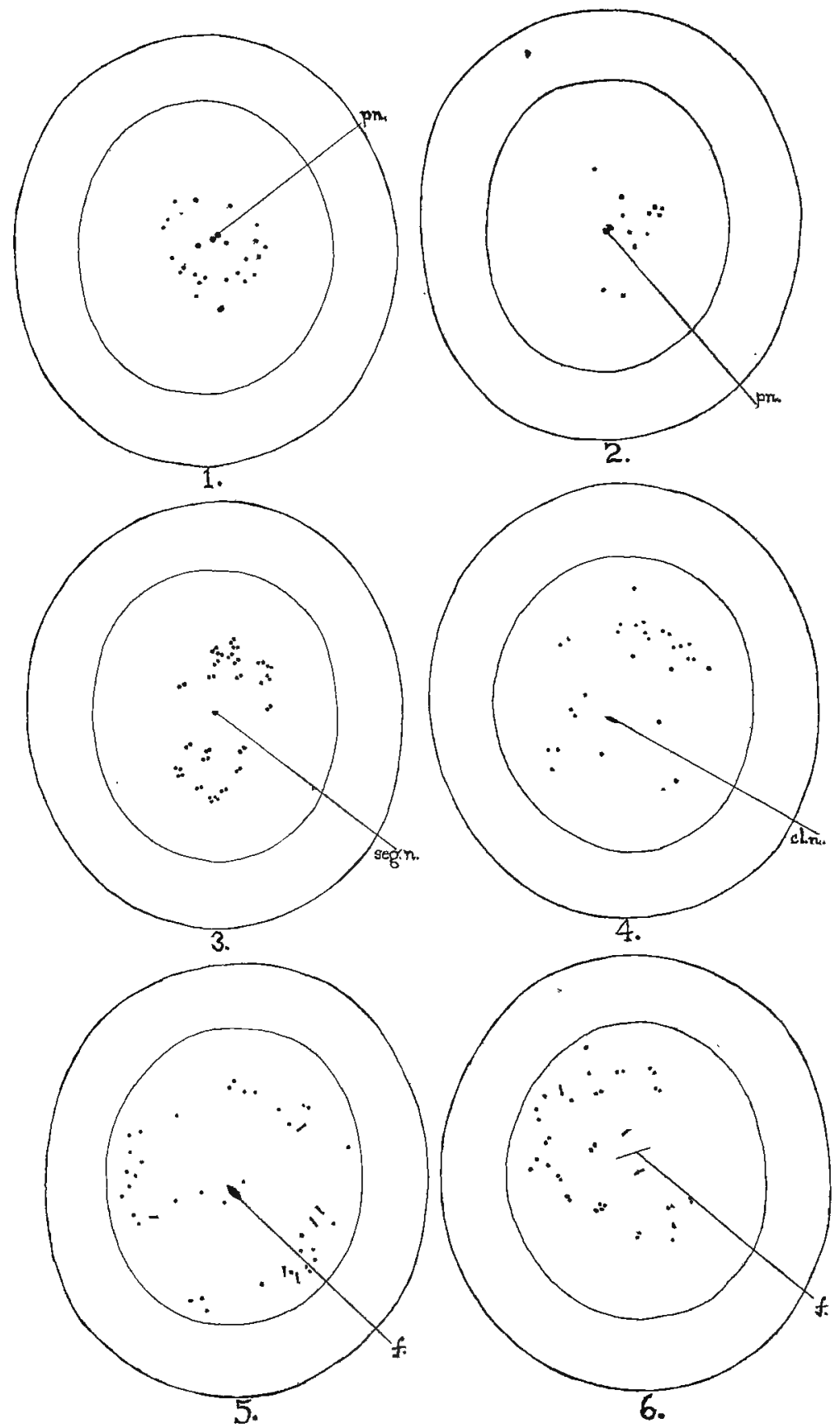

DIAGRAMS 1-6. NUMBER AND DISTRIBUTION OF ACCESSORY NUCLEI IN EARLY STAGES OF PIGEON'S EGG. 
EXPLANATION OF DIAGRAMS 1-6.

Diagram 1. Diagram showing number and relative position of accessory nuclei in the egg. The male and female pronuclei are in the center, lying in contact. Two sperm nuclei nearer than the rest. Same egg as in Fig. 11. $\times 10$.

Diagram 2. Pronuclei in closer contact. Same egg as shown in Fig. 12. Owing to the incompleteness of the series the number of sperm nuclei is too small. $\times 10$.

Diagram 3. Stage of segmentation nucleus. Accessory nuclei are mostly in pairs, indicating previous division. Same egg as Fig. $13 . \times 10$.

Diagram 4. Stage of first cleavage spindle. Same egg as Fig. $14 . \times 10$.

DIAGRAM 5. First furrow is beginning to appear at surface ( $f$ ). The two cleavage nucleit equidistant. Same egg as in Fig. $15 . \times 10$.

DIAGRAM 6. Beginning of second division. The accessory nuclei appear nearer the center of the disc than in the previous stage. $\times 10$. 
phenomena and amoboid movements occurring on the surface of the egg along the circle whose plane separates the two astral systems.

The Early Cleavages.-In Figs. 40-45 are shown the 2-4-8-16 cell stages, drawn from a surface view. The accessory cleavage is also shown, except in the sixteen-cell stage. The first furrow crosses the disc along its shorter diameter. It is slightly eccentric in position. In the four-cell stage is seen the so-called "cross furrow" connecting the second furrows. In the eight-cell stage, considerable variety exists in the position of the furrows. A more regular type is shown in Fig. 43, and an irregular one in Fig. 42.

The more regular type shows meridional furrows at quite corresponding positions in the four quadrants. In the sixteen-cell stage shown the accessory cleavage is not represented (Fig. 45). The nuclei in the anaphase of division are shown as they appeared in a surface view in a whole mount of the blastoderm, and give an idea of the relative size of nuclei and blastomeres.

In the sixteen-cell stage there is a clearly marked polarity of the egg due to the small size of the blastomeres on one side. This asymmetry of cleavage was pointed out by Kölliker in the case of the chick as producing an evident polarity during the early cleavages, whose relation, however, to the polarity of the embryo is undetermined.

\section{Development of the Accessory Nuclei.}

The accessory nuclei, whose appearance soon after the time of entrance was described in connection with Fig. 6b, have been found in later stages, varying considerably in number. In fertilization stages from twelve to twenty-five have been counted. After division sets in among them their number in some cases becomes very great, and no attempt has been made to count them. The diagrams (Diagrams 1-6) show the number and distribution of these nuclei in a series of stages. The general fact is disclosed that they migrate away from the point of entrance and soon become outside of the vicinity of the pronuclei. During the earlier stages of copulation one or more of the accessory nuclei may remain in the vicinity within the affected area of the germinal disc. But this is not true of the later stages, as is indicated by the absence of accessory nuclei in Figs. 14-16.

In Fig. 13 a single pair are found at one side, near the affected area. This pair are in close apposition, as if conjugating. Moreover, twentyfive pairs of such nuclei are found in this egg together with some earlier division stages. Some of the pairs are in apposition, but most of them are a slight distance apart, some being in a stage very soon after division. 
A difficulty is presented in finding the division stages, on account of the surrounding yolk. It must be remembered that these nuclei are not in the favorable region for observation in the center of the disc where the yolk granules are fewer, but they are migrating through the deeply staining surrounding region. Hence during the division stages when at their minimum size they are to be seen only under the most favorable circumstances. Several clumps of chromatin threads in the spireme and later stages were seen, enough to indicate the probable presence of other division stages. The resting nuclei are, of course, larger and easily seen. For the above reason the details of the first division of the nuclei have not been made out in the very limited material at hand. This difficulty, however, later disappears, and the mitotic division of these nuclei may be made out with perfect ease.

If the sperm nuclei divide before the cleavage nucleus, then the rate of division of the latter is a resultant of a slower and a faster rate. The rate of division of the unfertilized egg nucleus may be considered as approaching zero. There have been contradictory observations as to whether the unfertilized blastodisc of the chick may segment parthenogenetically. Appearances have been observed which at any rate suggest this. Barfurth, 94, offers a different explanation of these phenomena holding that there is no true cleavage in the unfertilized eggs. Assuming that possibly it may occasionally happen that the unfertilized egg nucleus may divide for several generations of cells, it is in accord with the accepted view as to the nature of the sperm protoplasm that the sperm nucleus should show a faster rate of division than the egg nucleus, and that the fusion nucleus should have a somewhat slower rate than that of the sperm nuclei. But Rückert found in the selachian egg that the sperm nuclei divide synchronously or nearly so, with the cleavage nucleus. Oppel, 92, found in the reptilia, on the other hand, that the accessory nuclei divided more slowly or not at all in many cases. It is thus seen that special adaptations have arisen in different groups. Environment seems to have more to do with the division of the sperm nuclei than the nature of their own protoplasm.

In the course of their further migration the nuclei reach the coarser yolk surrounding the inner zone of the germinal disc. Here, either because of a difference in the chemical nature of the materials surrounding them, or because their progress is impeded by the coarser yolk granules, the nuclei remain and their division is followed by a cleavage of the surrounding cytoplasm. The first indications of this accessory cleavage on the surface of the egg are seen when the first furrow is established between the cleavage nuclei (Fig. 40). The continuation of this cleavage and division of the surface into small cell-like areas is indicated in the 
two-, four- and eight-cell stages. In the later stages obtained the accessory cleavage is not shown in the figures. This accessory cleavage is then set up after the second mitotic division of the sperm nuclei. They are found at the time of this division surrounded by wide cytoplasmic areas free from yolk granules. The resting nuclei after the first division are accompanied by small areas of a "sphere substance" which entirely resembles this material. This sphere substance rather than being regarded as an organ accompanying the nucleus would seem to be an accumulation of the products of the nuclear activity. During the migration of the nuclei, the amount accumulated next to a nucleus appears small (Fig. 36), but after they are settled down the substance soon gathers in large quantities. Of course this statement is not meant to imply that the sphere substance may not at certain times take on a definite form, like a permanent organ, as in the young ova, for instance. According to the view of Van Bambeke, 97, the sphere substance is the center of formation of plastic and of nutritive elements.

To explain the peripheral migration of the sperm nuclei, Rückert has developed a theory of mutual repulsion which applies to all nuclei of a like character, and is exerted by and. through the means of the sphere substance. The sperm nuclei show a mutual repulsion for each other, which prevents their conjugation with one another. The cleavage nuclei have a superior power of repulsion, and so drive the sperm nuclei from the cleavage area into the yolk. The egg nucleus having no centrosome and sphere, or only a slightly developed one, is on the contrary attracted to the male pronucleus. The early and rapid migration of the sperm nuclei out of the cleavage area is, however, a fact which does not seem to fall within this explanation. The sperm nuclei for some reason migrate to the periphery and give rise to an accessory cleavage there, while the egg is still in the two-cell stage. Only a few straggling nuclei are at this time remaining within the inner area of the disc. There seems to be a tendency on the part of the sperm nuclei to migrate, only one of them being caught at the early stage by the attraction of the female nucleus; and this conclusion is certainly not inconsistent with the motility of the sperms during the stage of their free existence. As an active cause for the migration of the sperm nuclei, it might be assumed that the activity is but the continued expression of the labile nature of the protoplasm which gives the sperm its motile character during the period of its independent existence. An indication of the rapid movement of the sperm nuclei has already been pointed out, namely, that the accumulation of altered protoplasm or "sphere substance" about the nuclei while migrating in the germinal disc is very small. As soon, 
however, as they reach the marginal yolk they become surrounded by wide areas of protoplasm free from granules of yolk, owing, according to the assumption, to the cessation of their rapid movements and their delimitation to fixed areas, which results in the accumulation about them of the products of their metabolism, instead of its diffusion into the surrounding protoplasm.

Mitosis in the Sperm Nuclei.-The mitosis of the accessory nuclei appears to be normal in the early divisions, at least in the sense that it results in an equal division of the chromosomes. The details of mitosis have not been compared with that of the cleavage nuclei, although such a study might indeed be valuable. The determination of the number of chromosomes in the spindle has a bearing upon the origin of the nuclei, of course. It is not asserted, since it has not been definitely proved, that mitosis is always perfectly normal, even at this stage, since abnormalities do appear later which lead eventually to amitosis. No pluripolar spindles have, however, as yet been observed. Regular equatorial plate stages are found. The reduced number of chromosomes is present, which is eight. In the metabolic nuclei the chromatin network is somewhat finer than that of the cleavage nuclei. This difference extends to the fully formed chromosomes, which are narrower and somewhat more elongated than those of the cleavage nuclei. In the prophases very long, slender chromosomes are formed which become shorter and thicker as they approach the equatorial plate stage. A typical longitudinal splitting of V-shaped chromosomes takes place (Fig. 33), and as the daughter chromosomes pass to the poles, one end of each becomes thicker. Gradually the chromatin accumulates at this end (Fig. 34) until in the late anaphase the chromosomes appear as short oval bodies approaching a spherical shape (Fig. 35). The achromatic structures are well defined. The centrosome is a sharply dofined, deeply staining spherical granule, not so large as in the late cleavage nuclei, but decidedly more conspicuous than the centrosome of the maturation and early cleavage stages. The spindle fibers are distinct and the spindles are very regular in form. These characteristics of mitosis and their similarity to that found in later cleavage stages and dissimilarity with that found in the early cleavage seems clearly correlated with the nature of the substance by which the nuclei are surrounded, which is in the one case a highly plastic cytoplasm, the immediate product of the nuclear activity, and in the other is the largely unmodified egg cytoplasm, which from its coarse alveolar structure reacts differently to the mitotic forces and gives less evidence of their operation by a change in form than does the more plastic medium. 
In regard to the synchronousness of division in the sperm nuclei, there appears to be a considerable difference. In one egg of the two-celled stage, over one hundred sperm nuclei were present. The accessory cleavage began at one side and here the nuclei had nearly all passed into a resting stage. On the opposite side of the disc, the nuclei were nearly all in some phase of division from spireme to late anaphase. It did not seem that concentric zones could be distinguished, as Rückert has found to be the case in the selachian, in which the gradations in phase of division could be found in successive zones. Rather in this egg there was a difference in phase on opposite sides, or what may be called a polar difference. The evidence of this is seen also in the beginning of the accessory cleavage, as shown in Fig. 40.

\section{The Yolk Nuclei of Later Cleavage Stages.}

With the advance of the cleavage nuclei, the sperm nuclei are driven into the surrounding yolk. In a stage about fifteen hours after fertilization, the sperm nuclei were found dividing amitotically. The intervening stages have not been filled in. The identity of the yolk nuclei at this stage with the earlier sperm nuclei is undoubted in the light of the selachian egg, whose phenomena can be duplicated, at least as to chief details, in the pigeon.

Balfour has described the yolk nuclei in the chick as lying at the margins of the blastoderm, and under the peripheral cells, but not under the center. The nuclei are found very largely in nests or clusters, the members of which are very unequal in size. Sometimes 6-8 nuclei may be found thus clustered together (Figs. 39a, b, etc.). They are surrounded by wide areas of protoplasm free from granules of yolk. Besides the nuclear nests, many are found singly and these very frequently at the margin of the blastoderm near the surface. These often show a distinct difference in staining capacity, retaining the stain with more tenacity than the underlying ones. This difference would seem to be correlated with the environment, since these are found in the coarse, deeply-staining, yellow yolk and the underlying ones in the white yolk. There are also " giant" resting nuclei as large as the entire protoplasmic area which surrounds one of the nuclear clusters (Fig. 37b).

Transitional stages from mitotic to amitotic division may be found at this period. In some of the protoplasmic areas are found nests of daughter nuclei not yet reconstructed (Fig. 38). The separate chromosomes or chromatin vesicles are distinct or partially fused together. In some of the groups of chromatin vesicles approximately eight could be counted, although the exact number could not be identified on account 
of fusion, and also apparent disintegration of some. 'These appearances may arise from pluripolar spindles, which have not yet been found in the pigeon, but which are undoubtedly to be found here as in the selachian. Other evidences of attempts at mitosis are to be found. Often a spireme is found of irregular appearance, indirect division proceeding no farther. There were no accessory cleavage furrows recognized at this stage.

Are the nuclei incorporated into the cleavage area? There is no affirmative evidence on this point. On the contrary, there is a distinet separation between cleavage cells and yolk underneath the blastoderm, the marginal cells having complete cell boundaries. No nuclei at all resembling the yolk nuclei have been found within the cleavage area. The cleavage nuclei are distinct in appearance and are not easily to be confused with the nuclei in the yolk.

The only evidence obtained having a possible bearing on the fate of the yolk nuclei is the occurrence of great numbers of peculiar refractive bodies closely associated with the nuclei in the large nuclear nests. These kodies resemble the disintegrating nucleoli of the late ovarian egg. In a nest such as shown in Fig. 38 there are large masses of this refractive substance made up of clusters of vesicles. There are also isolated rod-like bodies of the same material. May these not indicate that there is a constant reduction in the amount of chromatin material due to "karyolitic" action? The yolk nuclei are very numerous at this stage, and form a fringe around the blastoderm, but do not go far out into the yolk. Their numbers at the start, if augmented by division followed by migration, ought soon to fill the yolk, as it would seem. On the contrary, the margin of the blastoderm seems to be the only region occupied by them. The liquefied products of this karyolitic action are doubtless absorbed by the embryonic cells. The refractive bodies are probably material in process of dissolution, as is apparent in the case of the nucleoli of the late ovarian egg.

\section{Polyspermy in Other Eggs.}

The term physiological polyspermy has been applied to all cases where more than one spermatozoon normally enters the egg. The fate of the supernumerary sperms is by no means the same in the different groups in which the phenomena occur. Hitherto, in the elasmobranchs alone has their persistence to form yolk nuclei or " merocytes" been observed. The nearest approach to this condition was found by Oppel, 92, in the reptilia, where the sperm nuclei though present in large numbers, divided slowly and karyolitically, and soon degenerated. The evidence in the case of the reptilia is, however, fragmentary. 
If the cause assigned by Rückert for the occurrence of physiological polyspermy be correct, namely, the absence of protection against it on account of the thinness of the egg covering in these internally fertilized eggs, it might well be expected to occur in the bird's egg also. Balfour, 85, stated in regard to the chick, that "In the bed of white yolk nuclei are present which are of the same character and have the same general Iate as in Elasmobranchs. They are generally more numerous in the neighborhood of the thickened periphery of the blastoderm than elsewhere."

Among the amphibia, polyspermy has been found in the urodela. Thus Jordan, 93, found it to be universal in the newt. He states that "there is every reason for regarding such physiological polyspermy in the newt us a natural, normal and in fact usual occurrence." The extra nuclei degenerated shortly after the fusion of the pronuclei. Fick, 92-93, found polyspermy occurring in axolot], but inconstant. Braus, 95, in triton found the sperm nuclei dividing amitotically from the start, a fact which Rückert correlates with the entrance of the spermatozoa through the yolk, since in elasmobranchs the sperms enter through the germinal disc and change from the mitotic to the amitotic method of division after they have migrated into the yolk. The anura, on the other hand, are monospermic according to the evidence of Hertwig, Born, 86, Roux, 8I, and King, or, although opposing observations were recorded by Kupffer, 82, in the case of Bufo.

In the elasmobranchs the yoll nuclei have been the subject for much controversy and speculation. Balfour, 74, recognized the existence of such nuclei in the late cleavage stages of the selachian blastoderm. He surmised that they arose spontaneously in the yolk. Schultze, 77, disagreed with such an assumption as to their origin and took it for granted that they arose from the cleavage nuclei. Rückert, 85 , traced these free nuclei as far back in development as the eight-cell stage, which was the earliest stage he found. He argued that they arose from an equatorial cleavage of the nuclei of the four-cell stage, and that their position in the yolk indicated that they were the homologues of the nuclei of the vegetative pole in the frog's egg. Their peripheral position was taken as strongly favoring such an homology. Rückert termed them "merocytes," indicating thereby that they were parts of cells, namely, the nucleus with some surrounding protoplasm, which after division migrated awiay from the cellular region into the yolk. Kastschenko, 88, found these merocytes in the stage of the formation of the first furrow. He proposed a theory that the first cleavage nucleus gave rise to a multinucleate plasmodium before the first division of the egg. Rückert, 90-92, 
pursued the investigations still further, and by the discovery of fertilization stages, was enabled to announce the origin of the much-discussed yolk nuclei from spermatozoa. He thus not only accounted for the origin of the merocytes, but established the fact of physiological polyspermy for the selachian group. He traced a continuous series of stages from the entering sperm head to the fully developed merocyte. He obtained finally the conclusive evidence of their origin from spermatozoa by determining that the dividing nuclei contained only one-half the somatic number of chromosomes. Rückert's results for selachians were confirmed by Samassa, 95, Beard, 96, Sobotta, 96. His own complete account appeared in 1899.

The present state of the controversy which involves the ultimate fate of the merocytes is outside of the province of this paper. The question whether there may be another generation of yolk nuclei arising in late cleavage stages, homologous with the periblast of teleosts, has been the subject of controversy chiefly between His and Rückert.

The announcement of Rückert of the origin of merocytes from spermatozoa necessitated the modification of the prevalent assumption as to the universally pathological nature of polyspermy and opened up a field of inquiry as to the causes of normal polyspermy; its adaptiveness; its difference from the so-called pathological type; the influences which prerent multiple conjugation with the egg nucleus; the cause of the migration of the supernumerary sperms into the yolk; their change from mitotic to amitotic division, etc. The identification of these sperm nuclei with the long known "yolk nuclei," to which had been assigned by common assumption the function of yolk digestion for the embryo, both in selachians and teleosts, raised the question whether in reality in the selachians the sperm nuclei have a normal or physiological role in embryonic development.

As mentioned above, the presence of nuclei in the yolk during the early cleavage stages, forming a syncytium supposedly derived from the cleavage nuclei, had been used as an argument to support the theory of the homology of the yolk of the selachian egg with the lower pole cells of the frog's egg.

Rückert holds that the cause of polyspermy in the selachian egg is simply the absence of protection against it, due to the thinness of the egg membrane. The phenomena of conjugation of sperm nuclei with each other and their multiple conjugation with the egg nucleus, seen in the case of nicotinized eggs (Hertwig, 87), he holds to be due not to polyspermy, per se, but to changes brought about by nicotinization. Such phenomena are absent in polyspermatic eggs, and he proposes a theory that 
the sperm nuclei exhibit normally a repulsion for each other due to the presence and activity in some way of their accompanying sphere substance. The absence or feebler development of the sphere substance in the egg nucleus accounts for the mutual attraction displayed by the male and female pronuclei. Moreover, the mutual repulsion of sperm nuclei disappears with the change of their environment from the germinal disc to the yolk as it disappears in the abnormal environment of nicotinized eggs. Hence conjugation of nuclei occurs in the yolk, giving rise to giant nuclei, pluripolar spindles and progressively increasing irregularity of division ending in amitosis.

As to the adaptation of polyspermy to the large meroblastic egg, Boveri suggested that polyspermy was necessary in the case of the large egg to insure certainty of fertilization. Rückert maintains that the force of this argument is weakened by the fact that the region where the sperms may enter is very limited and is in close proximity to the egg nucleus. Sobotta accepted the above view of Boveri and also argued that the size of the egg was the factor which prevented multiple conjugation with the egg nucleus, since the sperms could never in so large an egg enter at exactly the same time. Hence they would always be unequal in development, and the largest would become the male pronucleus. Rückert points out the inconsistency of maintaining that the size of the egg requires the entrance of many sperms to insure fertilization, and that the size of the egg is also what prevents multiple fertilization. Rückert believes that the mutual repulsion of sperm nuclei is at least to be regarded as a fact in the selachian egg, if not proved true for all monospermic eggs. He thinks it improbable that the spermnuclei have a normal function in the embryonic development, and leaves open the question of a possible second generation of nuclei arising from the cleavage cells in later stages homologous with the periblast of teleosts.

As to the cause of migration of the aocessory nuclei into the yolk, Rückert adduces his theory of repulsion, holding that the sperm nuclei are driven from the germinal disc by the advancing cleavage nuclei, owing to their superior power of repulsion. If the observations upon the pigeon in this regard prove anything, it is that the sperm nuclei migrate so early to the periphery of the germinal disc that it is difficult to believe they do this under the influence of the cleavage nuclei. As pointed out, they are found in the accessory. cleavage region, far removed trom the affected area in the center of the disc, which seems to be the sphere of influence of the cleavage nuclei, as early as the formation of the first cleavage furrow. Moreover, they are nearly absent from the intermediate region at this time. This seems to point to the independent 
activity of the sperm nuclei, rather than any mechanical driving of them from the inner region. What chemotactic influences there may be present we of course have no means of knowing.

\section{Some Features of Mitosis in the Pigeon's Egg.}

Centrosomes and asters are structures which are frequently asserted to be absent from eggs heavily laden with yolk. For example, in the maturation stages of some amphibians they are said to be wanting. Speaking of the egg of unio, Lillie says that "rays form more readily in protoplasm free from yolk granules." The bird's egg is certainly as heavily laden with deutoplasmic granules as any, and these granules are of relatively large size.

This question cannot be considered properly without taking into view more than the earliest phases of development. If we take these into view in connection with the later cleavage, we find that there is a progressive increase in the distinctness of achromatic structures as development proceeds. A typical mitosis from a rather late cleavage stage is shown in Fig. 29. Here the centrosome is a very large, well-defined granule, and spindle and astral fibers are distinct.

In inquiring into the reason for the feeble development of astral fibers in the maturation stages of the pigeon's egg, it does not seem that the interference of yolk granules in all cases accounts for the fact. For occasionally yolk granules are not especially near to the spindle, and the structures in question are not exceptionally well developed in these cases. In the maturation stages in the pigeon's egg, the spindle is sometimes in an area free from granules, but the achromatic structures are essentially similar in all cases. Centrosomes and asters are inconspicuous, but the alveolar structure about the poles of the spindle, when copied with the camera, shows a somewhat regular radiate arrangement. There is no well defined centrosome, more than perhaps a cluster of minute granules difficult to make out.

Some light is thrown on this matter of asters and centrosomes by mitosis in the sperm nuclei. As has been pointed out, these nuclei when they reach the periphery of the disc in their migrations, come to rest and become surrounded by large areas of cytoplasm, which is identical in appearance with the sphere substance associated with the nuclei earlier. As has been suggested, this cytoplasm is apparently the product of the activity of these nuclei, and is evidently of a highly plastic nature, giving rise in division to very regular mitotic figures, and well defined centrosomes.

In the later cleavage stages of the blastoderm, the same is true. The 
nuclei then are surrounded by entirely similar areas. They are at this stage limited in their movements by the cell boundaries, and so confined to very small areas. Consequently they become surrounded by cytoplasm, which is the product of their own activity in altering the constituents of the yolk. This material is highly plastic and responds to the forces operating in mitosis so as to produce regular figures.

Compare with the limited movements of these nuclei the wide migrations of the nuclei resulting from the first cleavage, and we see that the latter have no chance to become surrounded by an altered material, since all products of nuclear activity must rapidly become diffused into the surrounding cytoplasm. The reason for the different appearance in mitosis is seen when we compare the alveolar structure of the unaltered egg cytoplasm with that surrounding the later cleavage nuclei. The criginal egg cytoplasm is coarser, i. e., the alveoli are larger, and takes the cytoplasmic stains much less deeply. This is not very apparent in the drawings. In the maturation stages the absence of a metabolic phase of the nucleus for so long a period makes the surroundings of the nucleus least favorable of all apparently for the production of typically regular figures. It has been noted by some observers that the second maturation division differs from. the first in the poorer development of asters, a phenomenon which might be due to the altered character of the surrounding cytoplasm. It would seem in the case of the pigeon's egg that the hyaline zone surrounding the first polar spindle (Fig. 6a) is not reformed so conspicuously at the second division, there being only scattered vacuoles present at this period in the region surrounding the nucleus. The suggestion that the deutoplasmic granules surrounding the nucleus in these early stages inhibit the formation of achromatic structures is perhaps an incomplete explanation, since the nature of the cytoplasmic groundwork may be a more fundamental cause.

\section{Conclusions.}

1. As a result of the monogamous habit of pigeons, ovulation is normally held in abeyance till aroused by the stimulus received from the male. The passivity of the female is compensated by the highly developed and complex instincts of the male bird. The determination of the time of fertilization and egg-laying must date from the time of mating. The second egg of a pair is set free from the ovary and enters the oviduct within a few hours 'after the first is laid. The egg is impregnated before entering the oviduct.

2. Polyspermy is normal. The most favorable region for entrance of sperms is the "fovea," in a zone surrounding the egg nucleus. Never 
Inore than one male nucleus has been found in very close proximity to the egg nucleus.

3. The stage of development of the egg may be approximately inferred from its position in the oviduct. The first polar spindle is formed in the ovarian egg. The first cleavage occurs about the time the egg is entering the shell-gland. The time elapsing between impregnation and the first cleavage is apparently between two and three hours.

4. The polar bodies lie within the egg membrane, in a depression in the cytoplasm. The second disintegrates before the first, showing a tendency to form a network and become metabolic like the egg nucleus.

5. There is an area of active protoplasm surrounding the nucleus which during the maturation stages is oriented as a cone with the spindle at its apex, from which the polar bodies are pinched off. In preparation for cleavage, this area becomes oriented horizontally in the germinal disc. It undergoes amcboid changes and displays a differentiation into an outer hyaloplasmic and an inner granular area. It elongates in the direction of nuclear division, and divides with the division of the nucleus. The appearance of amœboid movements dies out during the resting period of the nucleus, and reappears at the second division. One blastomere is more hyaloplasmic than the other, and shows more complex amcboid changes.

6. The supernumerary sperms which enter the egg pass from the point of entrance toward the periphery of the disc. The accessory nuclei undergo division earlier than the cleavage nucleus. At the margin of the inner disc they come to rest within the coarser granular material, and give rise to an accessory cleavage on the surface of the disc. They divide nutotically without abnormalities, so far as discovered at this stage. They contain the reduced number of chromosomes, which is eight. The chromosomes differ in shape from those of the cleavage nuclei and the maturation spindles, being more slender. In late cleavage these nuclei are found outside the blastoderm, at or near the margins, and dividing amitotically. Some traces of abnormal mitosis were found.

7. Asters and centrosomes were found in the maturation stages, though not conspicuously developed. There is a progressive increase in the distinctness of these structures as the nuclei become limited to narrower areas by cell division, so as to become surrounded by the more plastic cytoplasm resulting from their activity in altering the yolk. The less pronounced development of these structures in the maturation and early cleavage stages seems due to the nature of the cytoplasmic groundwork, as well as to the casual interference of yolk granules. The sperm nuclei likewise do not display well developed achromatic structures till they are 
delimited within narrow boundaries in the accessory cleavage area, when they become surrounded by large cytoplasmic areas free from yolk granules and display well developed and regular mitotic figures.

\section{BIBLIOGRAPHY.}

BALFOUR, 74.-A preliminary account of the development of the Elasmobranch fishes. Quart. Jour. of Micr. Sc., Vol. XIV.

78.-On the structure and development of the Vertebrate ovary. Jour. of Micr. Sc., Vol. XVIII.

- 78.-A monograph on the development of Elasmobranch fishes. London. VAN BAMBEKE, CH., 97.--Recherches sur l'oocyte de Pholcus Phalangioides. Arch. de Biol., XV.

BARFURTH, D., 95.-Versuche über die parthenogenetische Furchung des Hühnereies. Arch. f. Entw. 2 Bd., 3 Hft.

BEARD, 96.-The Yolk-sac, yolk and merocytes in Scyllium and Lepidosteus. Anat. Anz., Bd. XII, 1896.

BöнM, 88.-Ueber Reifung und Befruchtung des Eies von Petromyzon Planeri. Arch. f. Mikr. Anat., Bd. XXXII.

BokN, 86.-Biologische Untersuchungen, II. Arch. f. Mikr. Anat., Bd. XXVII. - 94.-Die Structur des Keimblaschens im Ovarialei von Triton taeniatus. Arch. Mik. Anat., XLIII.

BoverI, 92.-Befruchtung. Ergebn. d. Anat. u. Entwickelungsgesch.

BRADs, 95.-Ueber Zellteilung und Wachsthum des Triton-Eies. Jen. Zeitschr. f. Naturn., Bd. XXIX.

Carnor et Le Brun.-La Vesicule Germinative Chez les Batraciens. La Cellule, Vols. 13 and 14.

ConkLin, E. G., 99.--Protoplasmic Movement as a Factor in Differentiation. Wood's Holl Biol. Lectures.

Cushry, A. R., 02.-On the Glands of the Oviduct of the Fowl. Amer. Jour. of Physiol., Vol. VI, No. VII.

Frck, 92.-Ueber die Befruchtung des Axolotl-Eies. Anat. Anz., Bd. VII.

GuYeR, M. F, oo.-Spermatogenesis of Normal and of Hybrid Pigeons. University of Chicago.

Henking, 92.-Untersuchungen über die Ersten Entwickelungsvorgänge in den Eiern der Insekten, III. Zeitschr. f. Wiss. Zool., Bd. XLIV.

Hertwig, O., und Hertwia, R., 87.--Ueber den Befruchtungs und Teilungsvorgang des tierischen Eies unter dem Einfluss äusserer Agentien. Jena.

HIs, 97.-Ueber den Keimhof oder Periblast der Selachier. Arch. f. Anat. u. Entwickelungsgesch.

HoL,, M., 9o--Ueber die Reifung der Eizelle des Huhns. Sitzb. Acad. Wiss. Wien, XCrX, 3.

JoRDAN, E. O., 93.-The Habits and Development of the Newt. Jour. Morph., Vol. VIII, pp. 269-366.

Kastschenko, 88.-Zur Frage über die Herkunft der Dotterkerne im Selachierei. Anat. Anz., Bd. III, No. 9.

- 88.-Zur Entwickelungsgeschichte des Selachierembryos. Anat. Anz., Bd. III, No. 16. 
- 9o.-Ueber den Reifungsprozess des Selachiereies. Zeitschr. 1. Wiss. Zool., Bd. L.

KING, HeLeN DeAN, or.-The Maturation and Fertilization of Bufo Lentiginosus. Jour. of Morph., Vol. XVII, No. 2, pp. 293-350.

KUPFFER und BeNECKE, 78.-Der Vorgang der Befruchtung am Ei der Neunaugen. Festschr. f. Th. Schwann, Königsberg.

KUPFFER, C., 82.- -Ueber aktive Beteiligung des Dotters am Befruchtungsakte bei Bufo variabilis und vulgaris. Sitzb. d. Math.-phys. Klasse d. K. Bayer Akad, d. Wissensch.

- 9o--Die Entwickelung von Petromyzon Planeri. Arch. f. Míkr. Anat., Bd. XXXV, pp. 469-558.

LEBRUN, H., 02.-Maturation of the Eggs of Diemyctilus torosus. Biol. Bull., III, pp. 1-2.

LILLIE, Frank R., or.-The Organization of the Egg of Unio, based on a Study of its Maturation, Fertilization and Cleavage. Jour. of Morph., Vol. XVII, No. 2.

Michaedis, 97.-Die Befruchtung des Triton-Eies. Arch. 1. Mikr. Anat., Bd. XLVIII.

OPPer, 9r.-Die Befruchtung des Reptilieneies. Anat. Anz., Bd. VI.

92:-Die Befruchtung des Reptilieneies. Arch. f. Mikr. Anat,, Bd. XXXIX.

RÜCKeRT, 85.-Zur Keimblattbildung bei Selachiern. Sitzb. d. Ges. f. Morph. u. Phys. in München.

- 9o.-Ueber die Entstehung der Parablast oder Dotterkerne bei Elasmobranchiern. Sitz. d. Ges. f. Morph. u. Phys. in München.

9r.-Ueber die Befruchtung bei Elasmobranchiern. Verh. d. Ant. Ges. V. Vers. in München.

- 9x.-Zur Befruchtung des Selachiereies. Anat. Anz., Bd. VI.

- 92.-Ueber Physiologische Polyspermie bei Meroblastischen Wirbeltiereiern. Anat. Anz., Bd. VII.

- 92.-Zur Entwickelungsgeschichte des Ovarialeies bei Selachiern. Anat. Anz., Bd. VII.

— 99.-Die erste Entwickelung des Eies der Elasmobranchier. Festschrift zum Sieb. Geb. von Carl von Kupffer, Jena, 1899.

SAMASSA, 95.-Studien ueber den Einfluss des Dotters auf die Gastrulation und die Bildung der primären Keimblätter der Wirbelthiere. I. Selachier. Arch. f. Entwickelungsmech., Bd. II.

Schultz, Alexander, 75--Zur Entwickelungsgeschichte des Selachiereies. Arch. f. Mikr. Anat., Bd. II.

ScHULtz, 77.-Beitrag zur Entwickelungsgeschichte der Knorpelfische. Arch. f. Mikr. Anat., Bd. XIII.

Schultze, O., 87.-Untersuchungen über die Reifung und Befruchtung des Amphibien Eies. Zeit. f. Wiss. Zool, XLV, pp. 117-226.

SoвоттA, 96.-Ueber die Befruchtung des Wirbelthiereies. Sitzb. d. Würzb. phys.-mediz. Ges.

- 96.-Die Reifung und Befruchtung des Wirbeltiereies. Ergebn. d. Anat. u. Entwickelungsgesch.

—_ 96.-Zur Entwickelung von Belone Acus. Verh. d. Anat. Ges. X, Vers. Berlin. 
VIRснот, H., 97.-Ueber Unterschiede im Syncitium der Selachier Nach Ort. Zeit und Genus. Sitz. d. Ges. Naturf. Freunde zu Berlin, No. 7.

97.-Dotter Syncitium, Keimhautrand und Beziehungen zur Konkrescenzlehre. Ergebn. d. Anat. u. Entwickelungsgesch.

Whitman, C. O., 87. - The Kinetic Phenomena of the Egg during Maturation and Fecundation. Jour. of Morph., I, 2.

88.-The Seat of Formative and Regenerative Energy. Ibid., II.

ZIEGLER, H. E., u. ZIEGLER, F., 92.-Beiträge zur Entwickelungsgeschichte von Torpedo. Arch. f. Mikr. Anat., Bd. XXXIX.

ZTEGLER, H. E., 94.--Ueber das Verhalten der Kerne im Dotter der Meroblastischen Wirbeltiere. Ber. d. Naturf. Ges. Freiburg, i. B., Bd. VIII.

Hull Zoological Laboratory.

UNIVERSITY OF CHTCAGO, 1902.

\section{EXPLANATION OF PLATES.}

Plate I.

FIg. 1. Ovarian egg $1.4 \mathrm{~mm}$. in diameter, showing nucleus. $\times 120$.

FIGS. $1 \mathrm{a}$ and $\mathrm{b}$. Nuclei of ovarian eggs about $1 \mathrm{~mm}$. in diameter. $\times 312$.

Frg. 2a. Nucleus of ovarian egg $4 \mathrm{~mm}$. in diameter. $\times 120$.

FIG. 2b. Horizontal section through germinal disc of ovarian egg, $1 / 2$ inch in diameter, showing nucleus; $a$, group of chromosomes; $b$, chromatin network. $\times 120$.

FIg. 3. Nucleus of an ovarian egg $\% / 8$ of an inch in diameter. $\times 120$.

Fra. 4a. Vertical section through germinal disc and nucleus of ovarian egg, $3 / 4$ of an inch in diameter. $\times 50$.

Fig. 4b. Nucleus of same, enlarged; $a$, group of chromosomes; $b$, group of nucleoli; $c$, refractive substance; $d$, wall of nucleus; $e$, follicular envelope of egg, outer layers of capsular wall not shown. Combination of two sections. $\times 385$.

FIG. 5. Vertical section through disc of mature ovarian egg, taken from ovary after laying of first egg. Time, 7.30 P. M.; $a$, spindle; $B$, perivitelline layer; $c$, layer of substance free from deutoplasmic granules. $\times 200$.

FIG. 6. Surface appearance $\delta$ germinal disc about time of fertilization; $a$, inner area; $b$, outer zone; $c$, fovea. $\times 10$.

FIg. 6a. Horizontal section of germinal disc of egg loosed from ovary and not yet entered oviduct. Time, 9.00 P.M.; $a$, egg nucleus; $b$, sperm nuclei; $c$, poiar ring. $\times 125$.

FIG. 6b. Same enlarged, showing zone in which the sperm nuclei lie. $\times 1000$.

Fyes. 7a-h. Stages in transformation of entering sperms. $\times 2000$.

FIG. 7i. Inwandering follicular cell. $\times 2000$.

FIG. 8. Vertical section through disc showing second polar spindle, polar body and surroundings. Combination of two sections. Position in upper end of oviduct. Time, 7.45 P. M. $\times 200$.

FIG. 9. Vertical section, showing second polar spindle, polar body and surroundings. Time, 10.15 P.M. $\times 333$. 
FIG. 10. Vertical section. Pronuclei and surroundings. $\sigma^{\star}$ pron. at left. From two sections. Time, 11.50 P.M. $\times 400$.

FIG. 11. Vert. section, showing pronuclei. Time, 10.15 P. M. $\times 400$

FIG. 12. Vert. section, showing pronuclei and surroundings. Time, 10.40 P. M. $\times 200$.

FIG. 13. Vert. section, showing segmentation nucleus and surroundings. Pair of sperm nuclei at left. Time, 12 P. M. $\times 200$.

FIG. 14. Horizontal section, showing first cleavage spindle and surroundings. Position in oviduct at constriction between upper portion and shell gland. Time, 10.30 P. M. $\times 200$.

Fig. 15. Horizontal section, showing first pair of cleavage nuclei and surroundings. Combination of two sections. Time, 12 P.M. $\times 80$.

FIG. 16. Horizontal section showing first pair of cleavage nuclei at beginning of second division and surroundings. $n$, nucleus; $f$, first furrow. Position in shell gland of oviduct. Time, $1.00 \mathrm{~A} . \mathrm{M} . \times 80$.

\section{Plate III.}

FIG. 17. Horizontal section through nucleus of ovarian egg (Fig. 2D), showing group of chromosomes. $a$, pair of dyads; $b$, refractive substance in vesicular mass. $\times 2000$.

FTG. 18. Group of chromosomes in equatorial plate from a mature ovarian egg. Same stage as Fig. 5, but from a different egg. $\quad \times 2000$.

Fig. 19. Group of chromosomes in equatorial plate of first polar spindle, showing central spindle granules. From same egg as Fig. 6a. $\times 2000$.

FIG. 20. Vertical section, showing first polar spindle. Central spindle granules present as in 19, but not drawn. Egg clasped by funnel of oviduct. Time, 8.50 P. M. $\times 2000$.

FIG. 21. Vert. section, showing second polar spindle, not completely formed and first polar body. One chromosome not in equatorial plate. Combination of two sections. Time, 8.55 P. M. $\times 2000$.

Fig. 22. Vert. section, showing second polar spindle and first polar body. See Fig. 8. $\times 2000$.

FIG. 23. Vert. section showing second polar spindle and first polar body. Chromosomes are separating. Combination of two sections. Time 8.15 P. M., $\times 2000$.

Fig. 24. Second polar spindle. See Fig. 9.

FIG. 25. Vert. section, showing polar body, and egg nucleus as a fused mass of chromosomes. Combination of two sections. Time, 10.45 P. M. $\times 2000$.

FIG. 26. Vert. section, showing polar bodies, egg nucleus without definite membrane, inner sphere enlarged. Combination of two sections. Time, 8.55 P. M. $\times 2000$.

FIG. 27. Vert. section, showing completely reconstructed egg nucleus and polar bodies. Time, 8.30 P.M. $\times 2000$.

FIG. 28. Horizontal section showing first cleavage spindle in prophase. Chromosomes not drawn into equatorial plate. See Fig. $14 . \times 2000$.

FIg. 29. Spindle from cell of blastoderm about fifteen hours after fertillzation. Chromosomes not all shown. $\times 2000$.

F'IG. 30. Sperm nucleus from 2-cell stage of the egg. In prophase of division. $\times 2000$. 
Plate IV.

FIg. 31. Pair of sperm daughter nuclei. See Fig. 13 at left. $\times 1000$.

FIG. 32. Sperm nucleus in prophase of division. $\times 2000$.

Fra. 33. Sperm nucleus in division; shows chromosomes splitting. A vesicular refractive body and a yolk granule at right. $\times 2000$.

Fra. 34. Anaphase of division of sperm nucleus in polar view, lighter gi oup of chromosomes are in different plane. $\times 2000$.

Fig. 35. Late anaphase of division of sperm nucleus. Figures 30-35 are all from the same egg. $\times 2000$.

Frg. 36. Vert. section through blastoderm about fifteen hours after fertilization. Shows nuclei free in the yolk at the edge of the blastoderm. One nuclear nest is shown. $\times 120$.

Fig. 37. Similar to above. A "giant nucleus" is present in yolk. $\times 120$.

FIG. 38. From same egg as above. Shows an area in which two groups of chromatic staining bodies lie. $a$, chromatin vesicle; $b$, refractive body; $c$, yolk. $\times 2000$.

Figs. 39 a, b, c, d, e. Nuclei in yolk showing amitosis. $\times 1000$.

FIG. 40. Surface view of germinal disc showing first furrow and accessory clearage beginning at one side. Time, 12.20 A. M. $\times 10$.

Fig. 41. Surface view of four-cell stage, showing accessory cleavage. Time, 3.15 A. M. $\times 10$.

FIG. 42. Surface view of 8-cell stage with accessory cleavage. Time, 2.10 A. M. $\times 10$.

FIG. 43. Surface view of eight-cell stage. Accessory cleavage not shown. Time, 3.55 A. M. $\times 10$.

FIG. 44. Surface view of sixteen-cell stage. Accessory cleavage not drawn. $\times 10$.

Fra. 45. Surface view of sixteen-cell stage. Daughter nuclei are visible in a whole mount of the disc and are shown in the drawing. Accessory cleavage not drawn. The boundary represents the margin of the inner zone of the germinal disc. $\times 20$. 

FERTILIZATION AND EARLY DEVELOPMENT OF PIGEON'S EGG.

E. H. HARPER,

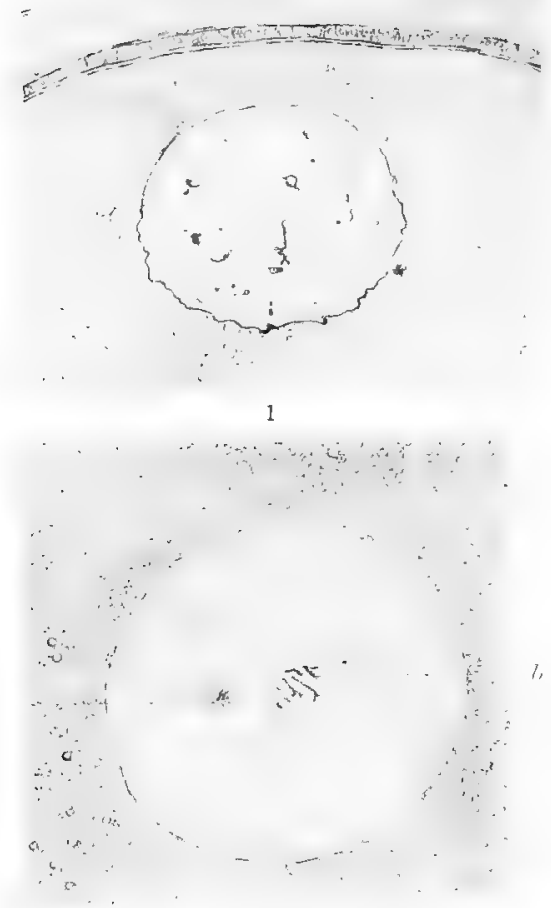

21
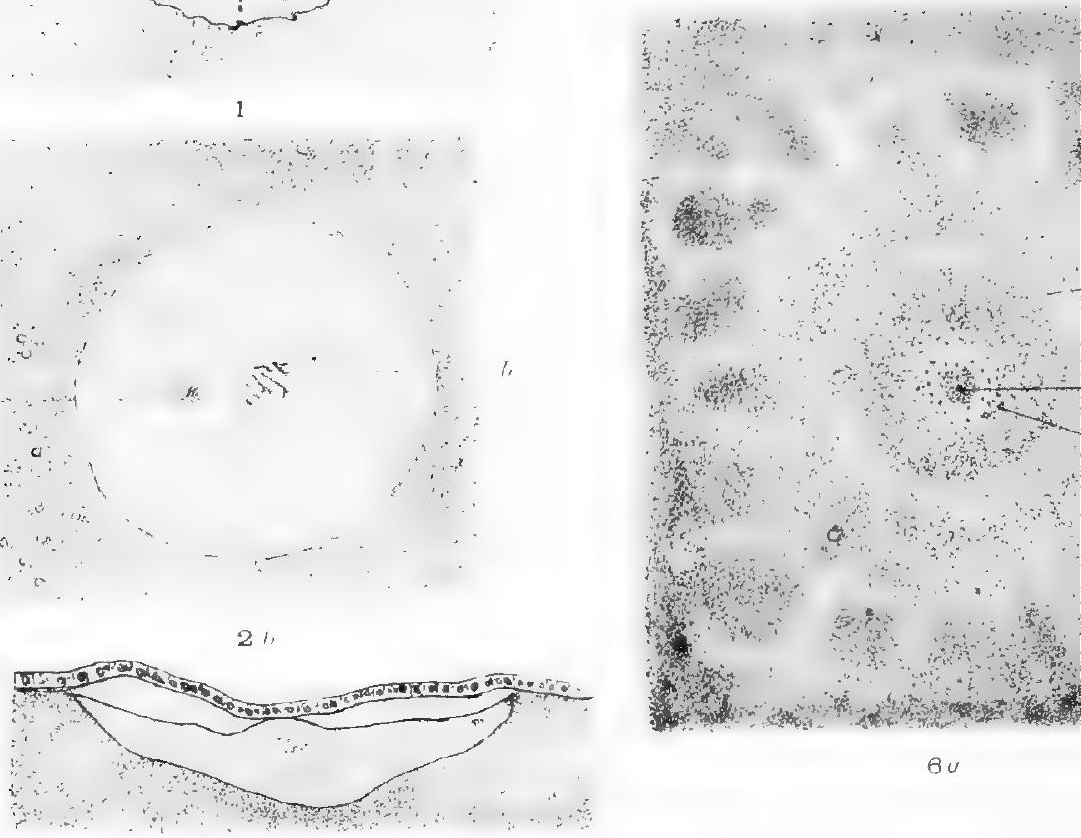

8u

3

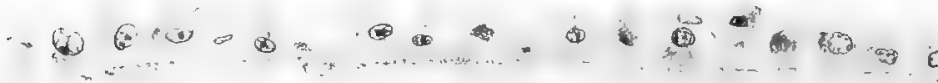

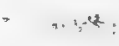




FERTILIZATION AND EARLY DEVELOPMENT OF PIGEON'S EGG.

E. H. HARPER.

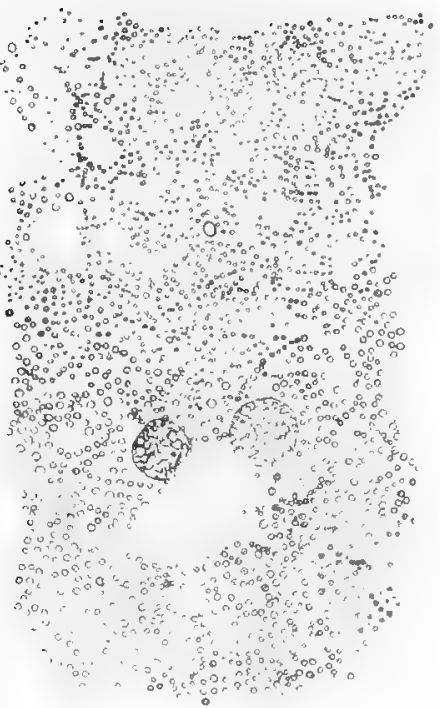

10

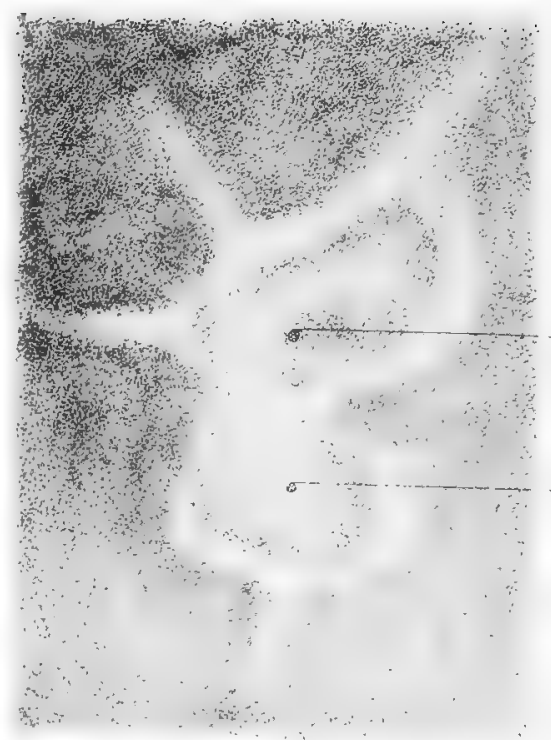

15
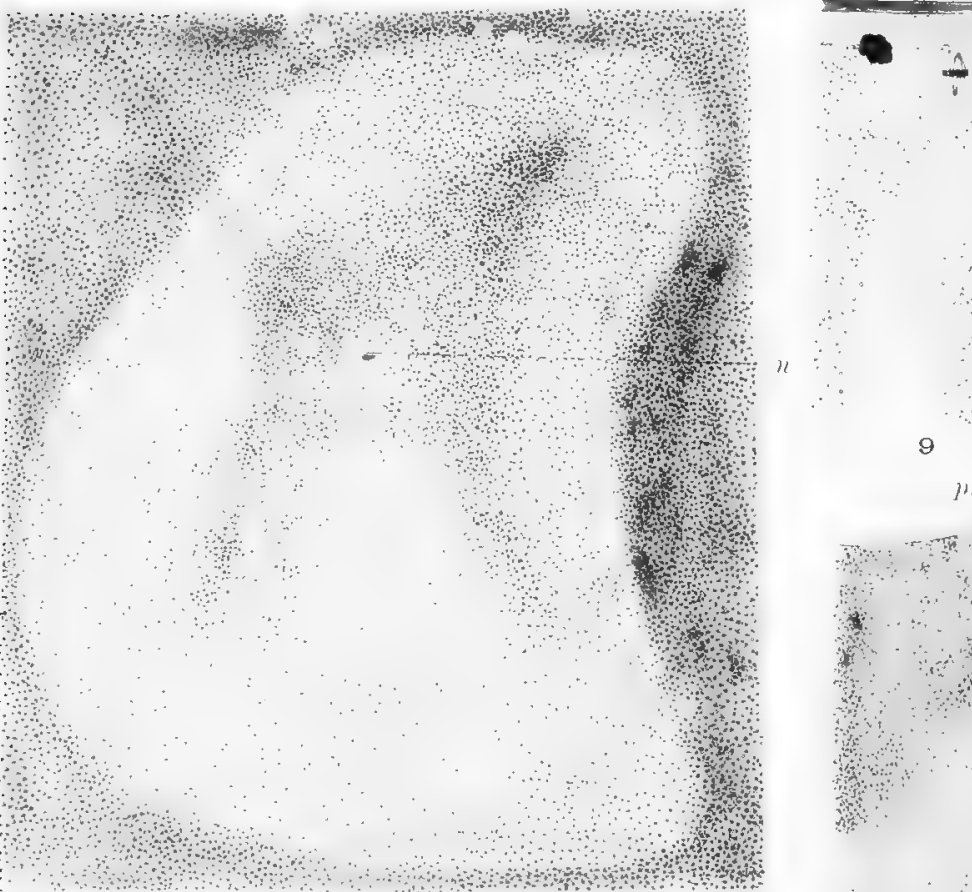

9

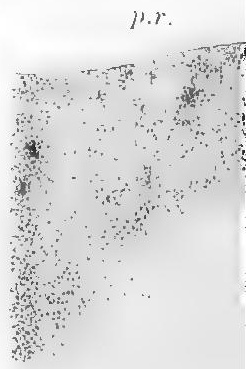




FERTILIZATION AND EARLY DEVELOPMENT OF PIGEON'S EGG.

E. H HARPER.
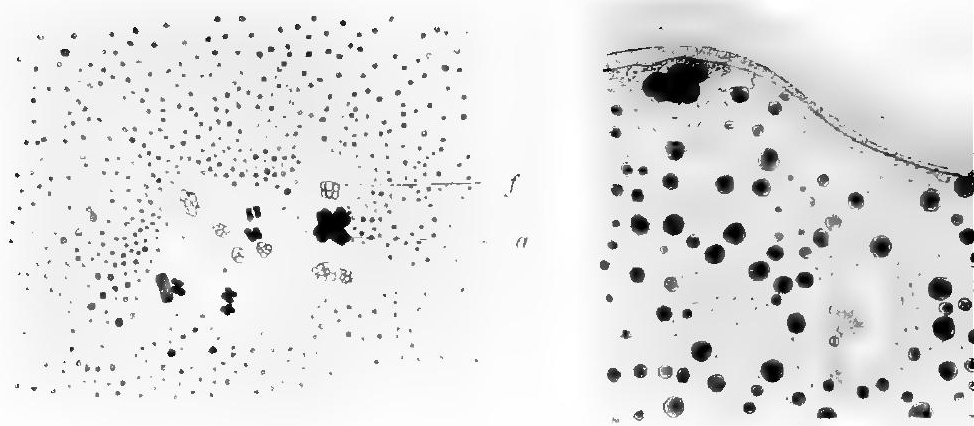

17

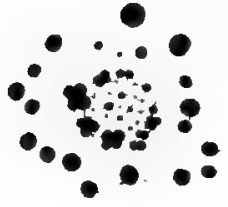

18

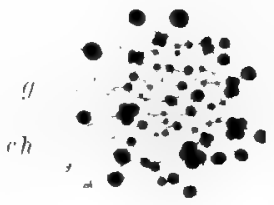

19

\section{8}
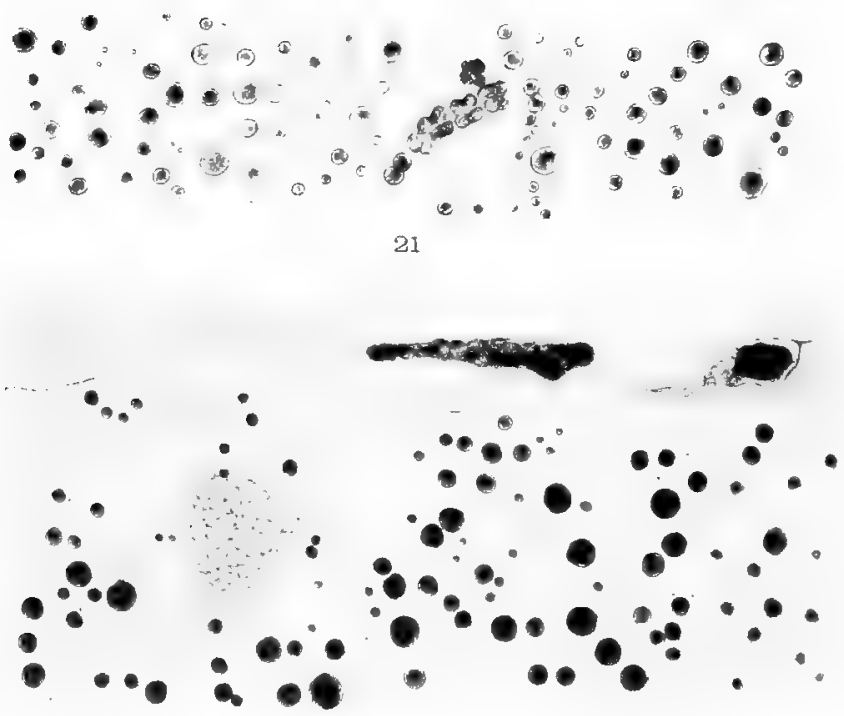


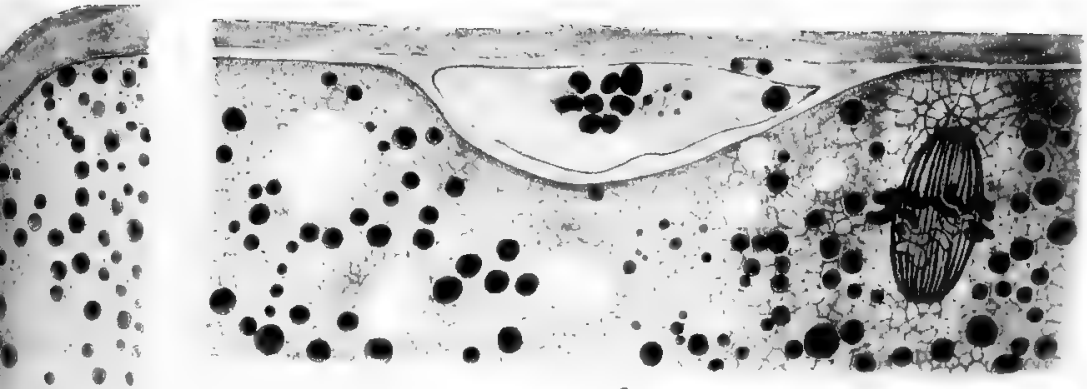

- 1

- 60.0
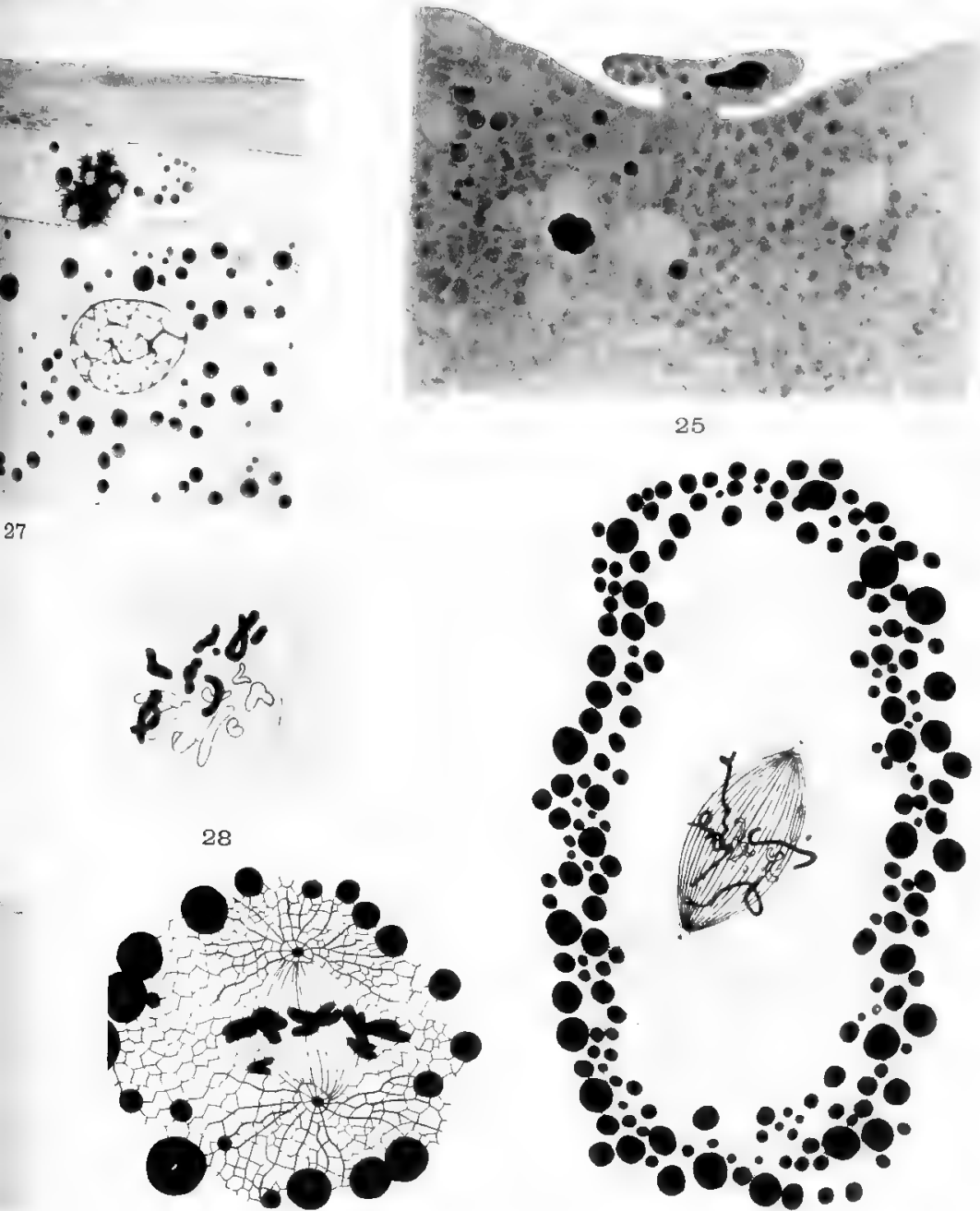

25

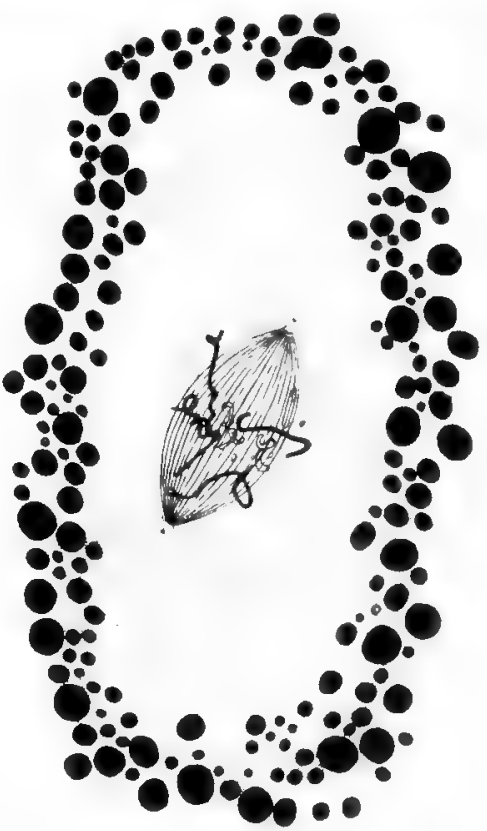




FERTILIZATION AND EARLY DEVELOPMENT OF PIGEON'S EGG.

E. H. HARPER.

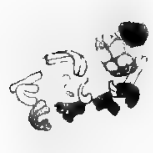

33

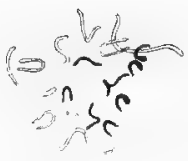

34

\section{S:}

35

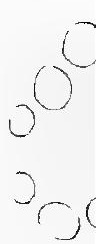

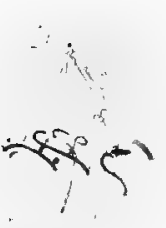

ty

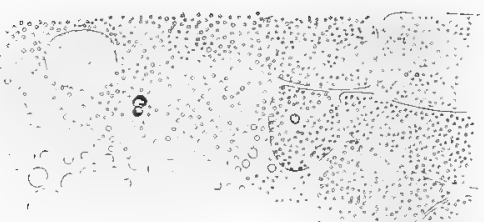

37

32

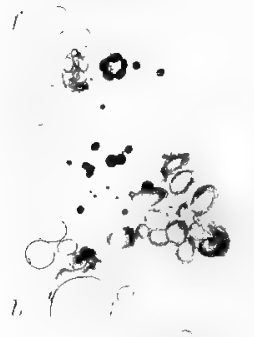

8

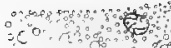

$\therefore$ Cor
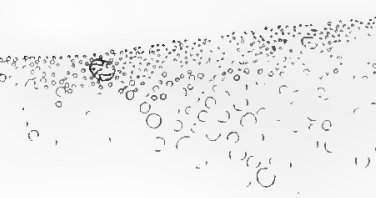

O

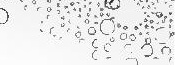






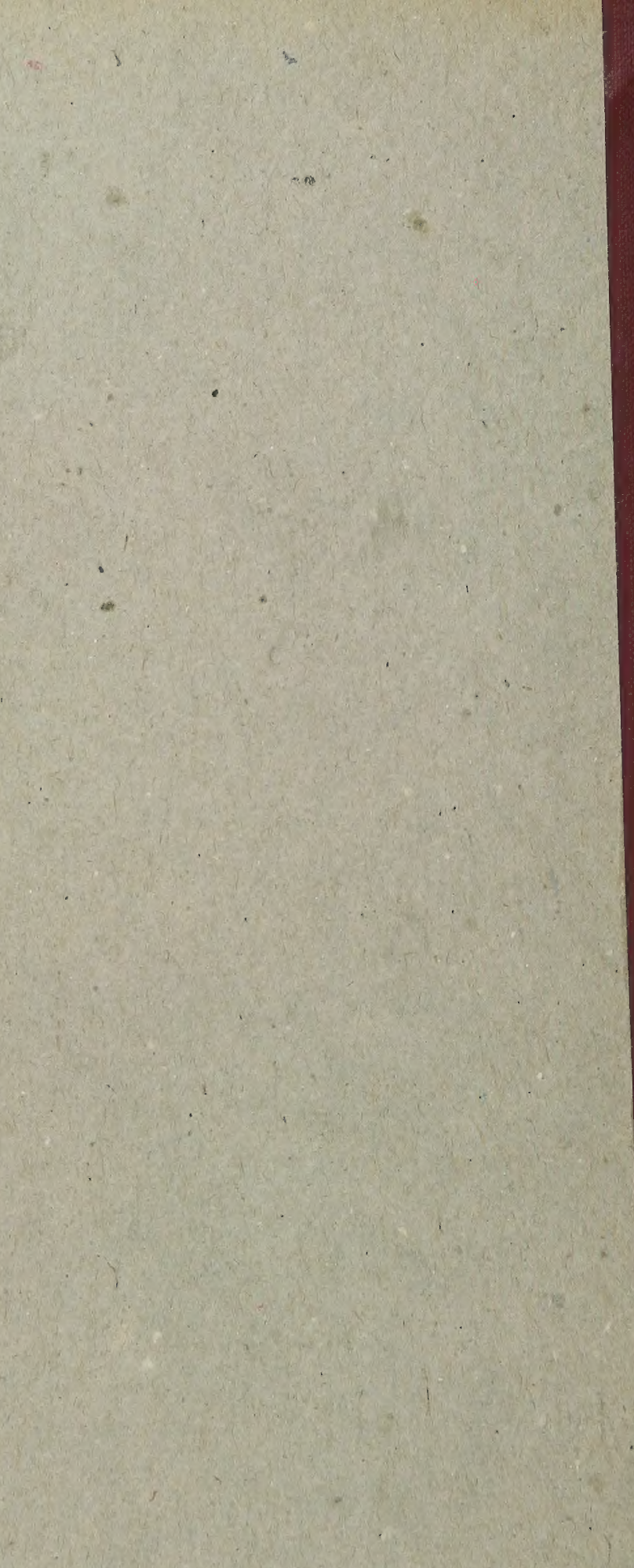

